\title{
A Geometric Model for the Beaufort/Chukchi Sea Thermohaline Structure
}

\author{
Peter C. Chu, Qianqian Wang,* and Robert H. Bourke \\ Department of Oceanography, Naval Postgraduate School, Monterey, California
}

(Manuscript received 11 September 1997, in final form 10 July 1998)

\begin{abstract}
A geometric model has been developed for analyzing observed Beaufort/Chukchi Sea temperature and salinity profiles based on their geometric features. It contains four major components: (a) a nonhomogeneous mesh difference scheme for second derivatives $\partial^{2} T\left(z_{k}\right) / \partial z^{2}$ and $\partial^{2} S\left(z_{k}\right) / \partial z^{2}$ at each data point $\left(z_{k}, T_{k}, S_{k}\right)$; (b) a set of key depths (depths of mixed layer, upper and lower thermoclines and haloclines, and deep layers) determined mostly by the geometric features of profiles, such as depths of minimum and maximum of $\partial^{2} T\left(z_{k}\right) / \partial z^{2}$ and $\partial^{2} S\left(z_{k}\right) / \partial z^{2}$ for shelf water and upper portion deep water; (c) modeled profiles $\hat{T}\left(z_{k}\right)$ and $\hat{S}\left(z_{k}\right)$, which are linearly interpolated from observed $T, S$ values at the key depths; and (d) statistical tests for accepting $\left[\hat{T}\left(z_{k}\right), \hat{S}\left(z_{k}\right)\right]$ as a good representative of $\left(z_{k}, T_{k}, S_{k}\right)$. The output of this geometric model is a set of major characteristics of each profile: sea surface temperature (salinity), mixed layer depth, upper- and lower-thermocline (halocline) depths, thermocline (halocline) temperature (salinity) gradient, and deep layer stratification. Analyzing 3562 Beaufort/ Chukchi Sea historical (1970-93) temperature and salinity profiles from the Naval Oceanographic Office's Master Oceanographic Observation Data Set by this geometric model, the Beaufort/Chukchi Sea thermohaline field reveals a dual structure: one layer (vertically uniform) on the continental shelf (depth $<150 \mathrm{~m}$ ) during winter and multiple layers (mixed layer, thermocline/halocline, sublayer) during summer. Strong seasonal variations were also found in mixed layer depth, upper thermocline/halocline depth, and strength.
\end{abstract}

\section{Introduction}

Determination of thermohaline structure (mixed layer, entrainment zone, thermocline, halocline) from observed temperature and salinity profiles is quite important in the Arctic Ocean for several reasons. First, the heat balance of the Arctic Ocean depends on the features of the mixed layer, entrainment zone, and thermocline. The mixed layer deepens by entrainment of water from the ocean below (Chu and Garwood 1991). The heat in the deep water is then transported to the surface. Second, the mixed layer acts as a buffer by storing solar heat input during the summer and releasing it back to the ice throughout the fall and early winter (Maykut and McPhee 1995).

Teague et al. (1990) developed a curve-fitting method to build upper-ocean $(0-400 \mathrm{~m})$ temperature and salinity climatology for the Generalized Digital Environmental Model (GDEM). The parameters they used are purely mathematical. To get physically meaningful parameters,

\footnotetext{
* Additional affiliation: Department of Atmospheric Sciences, Nanjing Institute of Meteorology, Nanjing, China.

Corresponding author address: Dr. Peter C. Chu, Department of Oceanography, Naval Postgraduate School, Monterey, CA 93943 5000 .

E-mail: chu@nps.navy.mil
}

Chu (1995) and Chu et al. (1997) proposed a parametric model based on a single type profile (mixed layer, entrainment zone, thermocline, deep layer) and an iteration scheme. The model consists of three major components: (a) a first-guess model profile, (b) high-resolution profiles interpolated from observed profiles, and (c) fitting of high-resolution profiles to the parametric model profile through iteration. The output is a set of major characteristics of each profile: sea surface temperature, mixed layer depth, thermocline depth, thermocline temperature gradient, and deep layer stratification.

The Chukchi Sea is a shallow sea with a mean depth of 40-50 m, having gentle knolls and several troughs that are shallow but with a relief that is a substantial fraction of the mean depth. The Beaufort Sea is a semienclosed basin with a quite narrow continental shelf $(30-80 \mathrm{~km})$ and a deep submarine canyon, the Mackenzie Canyon. The deepest water is confined to the bowl-shaped Mackenzie Canyon, which is enclosed by the $3000-\mathrm{m}$ isobath. The gradients in slope across the bottom are very large. The 150-m isobath approximately characterizes the Beaufort Sea shelf break (Fig. 1). The shallow continental shelf waters are readily affected by seasonally varying atmospheric conditions, such as heating, cooling, wind stress, and ice formation and melting. The seasonal variation of the water masses is remarkably large. Thus, we have two different types of profiles: (a) shelf profiles (water depth $\leq 150 \mathrm{~m}$ ) and 


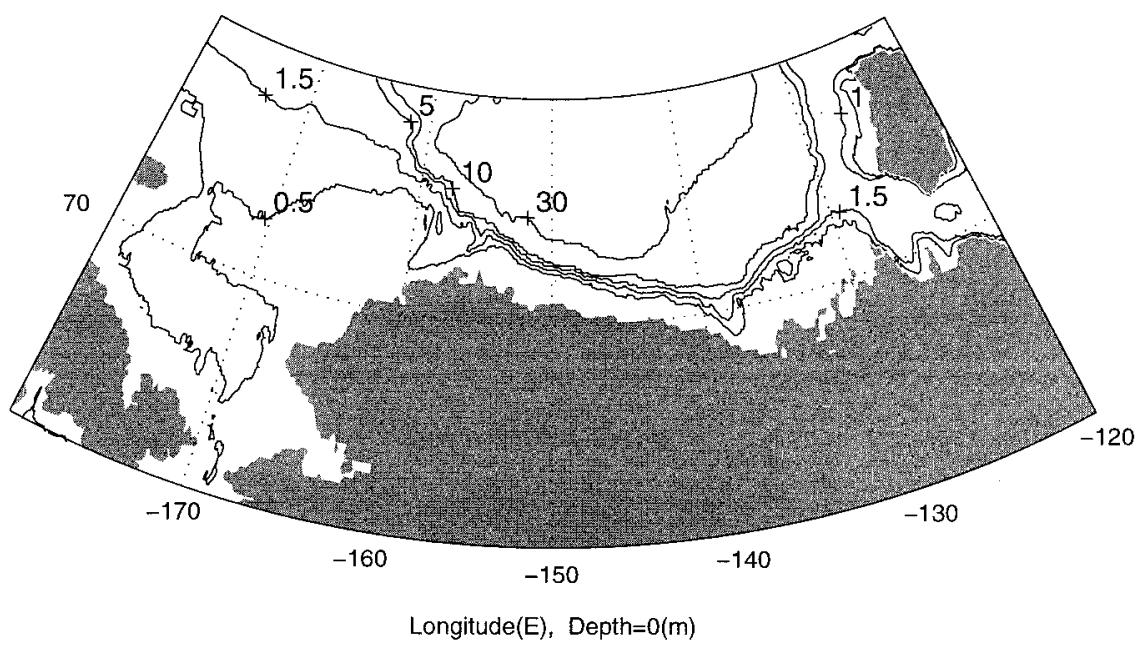

FIG. 1. The Beaufort/Chukchi Sea bathymetry. The data were obtained from the Naval Oceanographic Office DBDB5 world bathymetry database. Numbers show the depth in $100 \mathrm{~m}$.

(b) deep water profiles (water depth $>150 \mathrm{~m}$ ). Among the historical (1970-93) temperature and salinity profiles (3562) obtained from the Naval Oceanographic Office, 3384 profiles are shelf profiles and 178 profiles are deep water profiles.

The usefulness of the parameter model (Chu 1995; Chu et al. 1997) is based on the single-type approximation on profiles. If $T, S$ profiles follow the assumed pattern, the parametric model has a good capability to grasp major features of observed profiles. If $T, S$ profiles demonstrate multiple types, it is difficult to use the parametric model since the first-guess model profile is hard to determine. Thus, in this study we developed a new model to process multiple-type $T, S$ profiles in the Chukchi/Beaufort Sea based on the geometric features of the $T, S$ profiles, such as the depths of the minimum and maximum second derivatives $\partial^{2} T / \partial z^{2}, \partial^{2} S / \partial z^{2}$. With using the observed $T, S$ values at these depths (called key depths) and omitting any first-guess modeled profile, the geometric model transforms each profile into a set of characteristic parameters such as sea surface temperature (SST), sea surface salinity (SSS), mixed layer depth (MLD), temperature and salinity jumps across the entrainment zone $(\Delta T, \Delta S)$, upper- and lower-thermocline (halocline) depths and strengths, and the deep layer stratification.

\section{Master Oceanographic Observation Data Set (MOODS)}

The MOODS is a set of observed ocean data worldwide consisting of (a) temperature-only profiles, (b) both temperature and salinity profiles, (c) sound-speed profiles, and (d) surface temperatures from drifting buoys. It includes observations from various instruments such as conductivity-temperature-depth (CTD), salinity-temperature-depth (STD), low-resolution STD, expendable bathythermograph, and so on. These measurements are, in general, irregular in time and space. The data are compiled, archived, and updated by the Naval Oceanographic Office. In this study, we analyze temperature and salinity profiles acquired from CTD/ STD and bottle data. Our study domain includes the area $65^{\circ}-75^{\circ} \mathrm{N}, 120^{\circ}-180^{\circ} \mathrm{W}$; the dataset within this region during 1970-93 consisted of 3562 profiles after rejecting certain data during quality control. These primary editing procedures included removal of profiles with obviously erroneous location, profiles with large spikes, poor vertical resolution, and profiles displaying features that do not match the characteristics of surrounding profiles.

The main limitation of the MOODS data is its irregular distribution in time and space. Certain periods and areas are well sampled, while others lack enough observations to gain any meaningful insights. Vertical resolution and data quality are also highly variable, depending to a large extent on instrument type and sampling expertise. There is a data sparse area north of $73^{\circ} \mathrm{N}$ (Fig. 2a). The periods of 1971-72, 1977, 1979, and 1985-89 are found to have a relatively large number profiles averaging around 200 profiles per year (Fig. 2b). Most profiles were observed during the summer season (Fig. 2c). August logs the most observations (1253), 
ftbc24-all.dat(T/observation/point/3562)

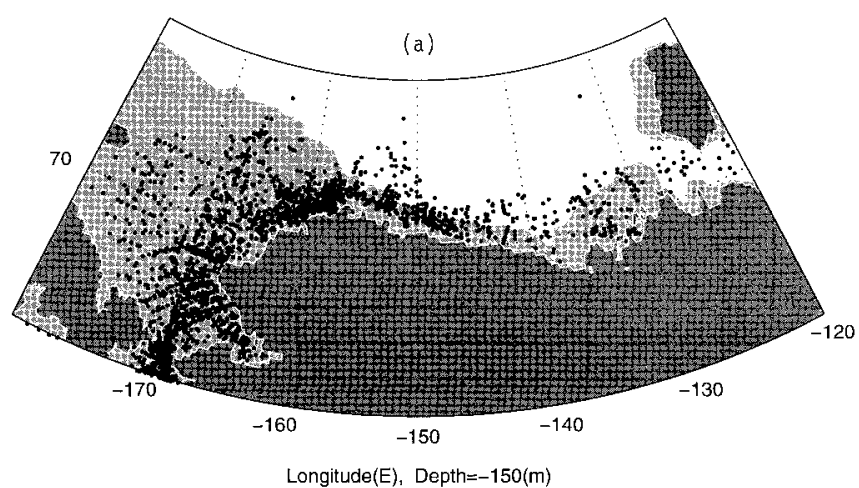

(b)

Longitude $(E)$, Depth $=-150(\mathrm{~m})$
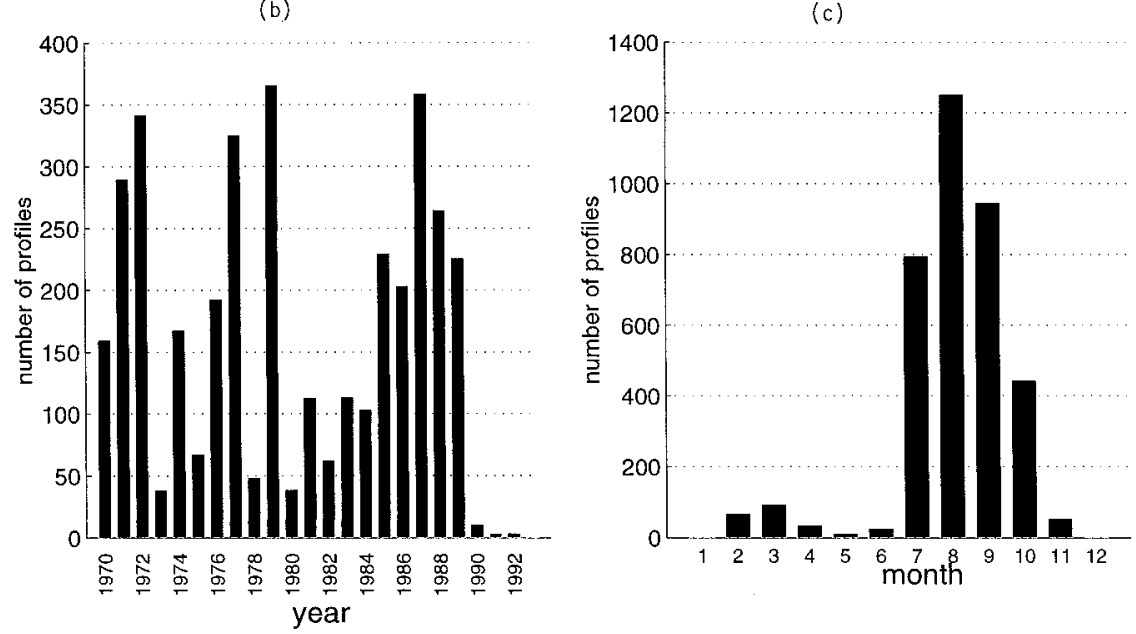

FIG. 2. MOODS data for this study: (a) distribution of stations, (b) interannual variation (1970-93) of number of profiles, and (c) seasonal variation of number of profiles.

while no observations have been recorded in the December and January dataset.

\section{Seasonal variation of temperature and salinity profiles \\ a. Basic features}

The surface radiative flux strongly affects the Beaufort/Chukchi Sea shelf thermohaline structure. During the winter (November-April), long periods of darkness together with low solar elevation give rise to a prolonged period of radiative loss from the surface. The radiative cooling at the surface destabilizes the upper layer through strong upward heat flux and salt rejection by ice freezing, and causes the formation of a deep mixed layer, which on the shallow shelves might reach the bottom resulting in an isothermal/isohaline structure (Figs. 3a,b). Different lengths of these profiles in the vertical are caused by the different water depths where the observations were taken (Fig. 1). During the summer (August), long daylight hours together with relatively high solar elevation give rise to a period of radiative deposition to the surface. The radiative warming at the surface stabilizes the upper layer through downward heat flux and freshwater influx by ice melting, causing the mixed layer to shoal and forming a multilayered structure (i.e., a mixed layer, upper and lower thermoclines and haloclines, and a deep layer), as shown in Figs. 3d,e. The number and spatial distribution of observations are much greater in summer than in winter (Figs. 3c,f).

In the deep water off the shelf the near-surface waters of the Beaufort Sea also experience seasonal variations. During the winter (November-April), surface cooling causes the formation of a deep thermal mixed layer (Fig. 4a). However, the surface salt flux caused by local ice freezing generates a relatively shallow salinity mixed layer (Fig. 4b). Below both the thermal and salinity mixed layers there exists a lower thermocline and halocline, appearing at 160-300-m depth (Figs. 4a,b). During the summer (August), surface warming and associated ice melting increase the SST (a maximum value near $8^{\circ} \mathrm{C}$ ), decrease the SSS (a minimum value near 20 psu), and cause both the thermal and salinity mixed 

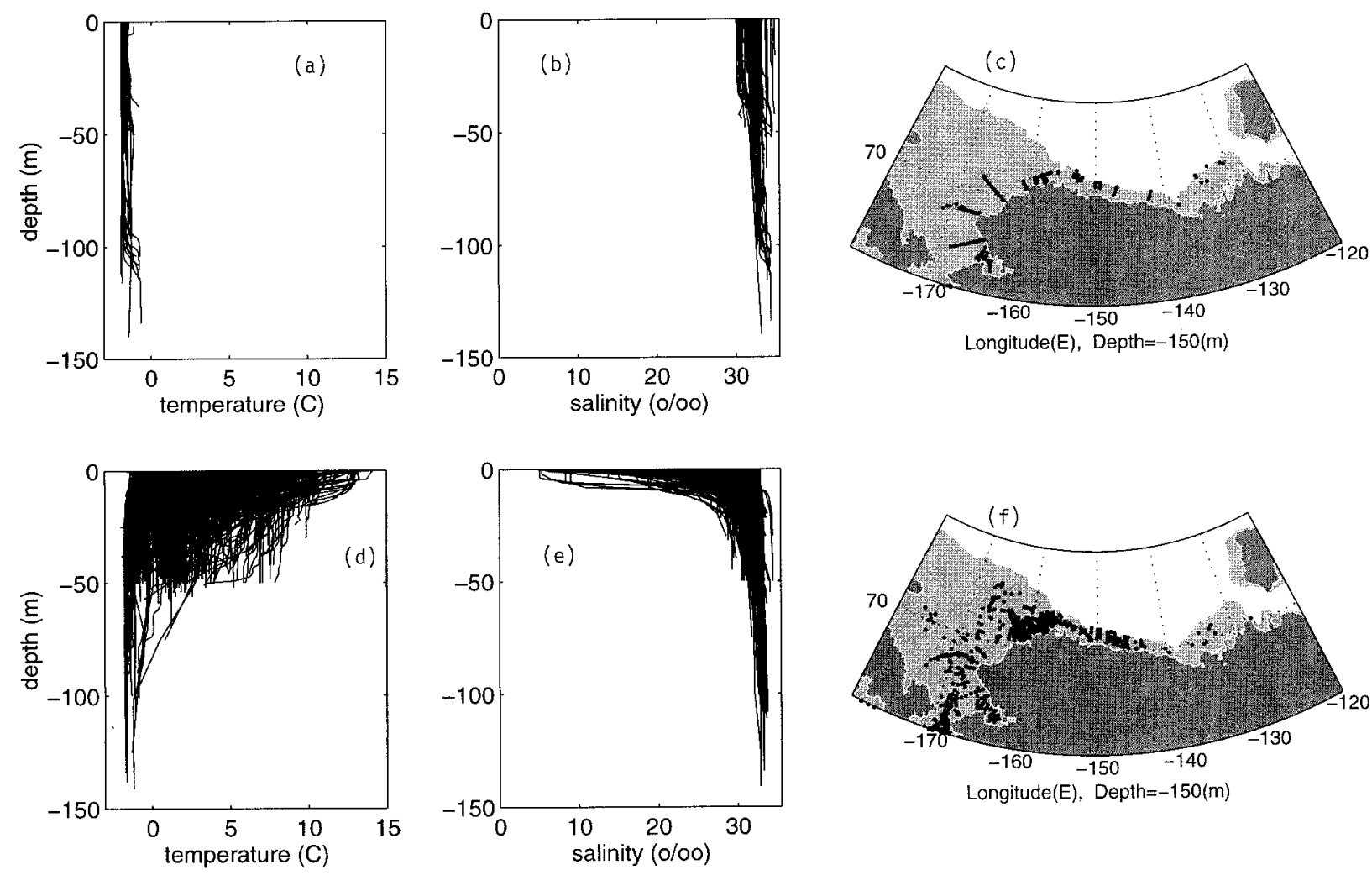

FIG. 3. Seasonal variation of $T, S$ profiles over the Beaufort/Chukchi Sea shelf water: (a) winter (Nov-Apr) $T$ profiles, (b) winter $S$ profiles, (c) distribution of winter stations, (d) summer (Aug) $T$ profiles, (e) summer $S$ profiles, and (f) distribution of summer stations. The shaded areas indicate shelf region (water depth $\leq 150 \mathrm{~m}$ ).

layers to shoal (Figs. 4d,e). We also notice that both winter and summer stations (Figs. 4c,f) do not extend far from the shelf break, and the intermediate waters (below 150-m depth) do not exhibit a seasonal variation.

\section{b. Classification of $T, S$ profiles}

The historical Beaufort/Chukchi Sea temperature and salinity profiles (Figs. 3 and 4) demonstrate the existence of several basic profile shapes, which we term deep mixing (DM), shallow mixing (SM), and advection (AD).

\section{1) DeEp MiXing (DM)-Type $T, S$ PROFILES}

The DM-type $T, S$ profiles are characterized by a single well-mixed layer in the shelf region (Fig. 5a) and a deep ( $\geq 150 \mathrm{~m}$ ) surface thermal mixed layer (Fig. 6a) and a thermocline in the deep water region. This type of profile is caused by surface destabilization, such as strong wind forcing, surface cooling, and brine rejection due to ice freezing. They are most prevalent during winter.

\section{2) Shallow MiXing (SM)-Type $T, S$ PROFILES}

The SM-type $T, S$ profiles are characterized by a multilayered structure (a shallow mixed layer, entrainment zone, thermoclines and haloclines, and a sublayer) in both the shelf region (Figs. 5b,d) and the deep water region (Figs. 6b,d). This profile type is generally present during the summer and is caused by surface stabilization, such as weak wind forcing, surface warming, and freshwater influx due to ice melting and river runoff, and therefore usually has a warm SST and a low SSS. Beneath the mixed layer the thermocline/halocline profile is complex, reflecting the seasonal adjustment. Thus, SM profiles feature a monotonic decrease of temperature with depth in the upper thermocline and a monotonic increase of salinity with depth in the upper halocline (Figs. 5b,d and 6b,d).

\section{3) Advection (AD)-TYPe $T$ PROFILES}

The AD-type $T$ profiles also have a multilayer structure (a shallow mixed layer, entrainment zone, upper and lower thermoclines, and a sublayer) in both the shelf region (Fig. 5c) and the deep water region (Fig. 6c). This type of profile, identified by a nose-shaped curve in the upper thermocline (monotonic increasing $T$ with 

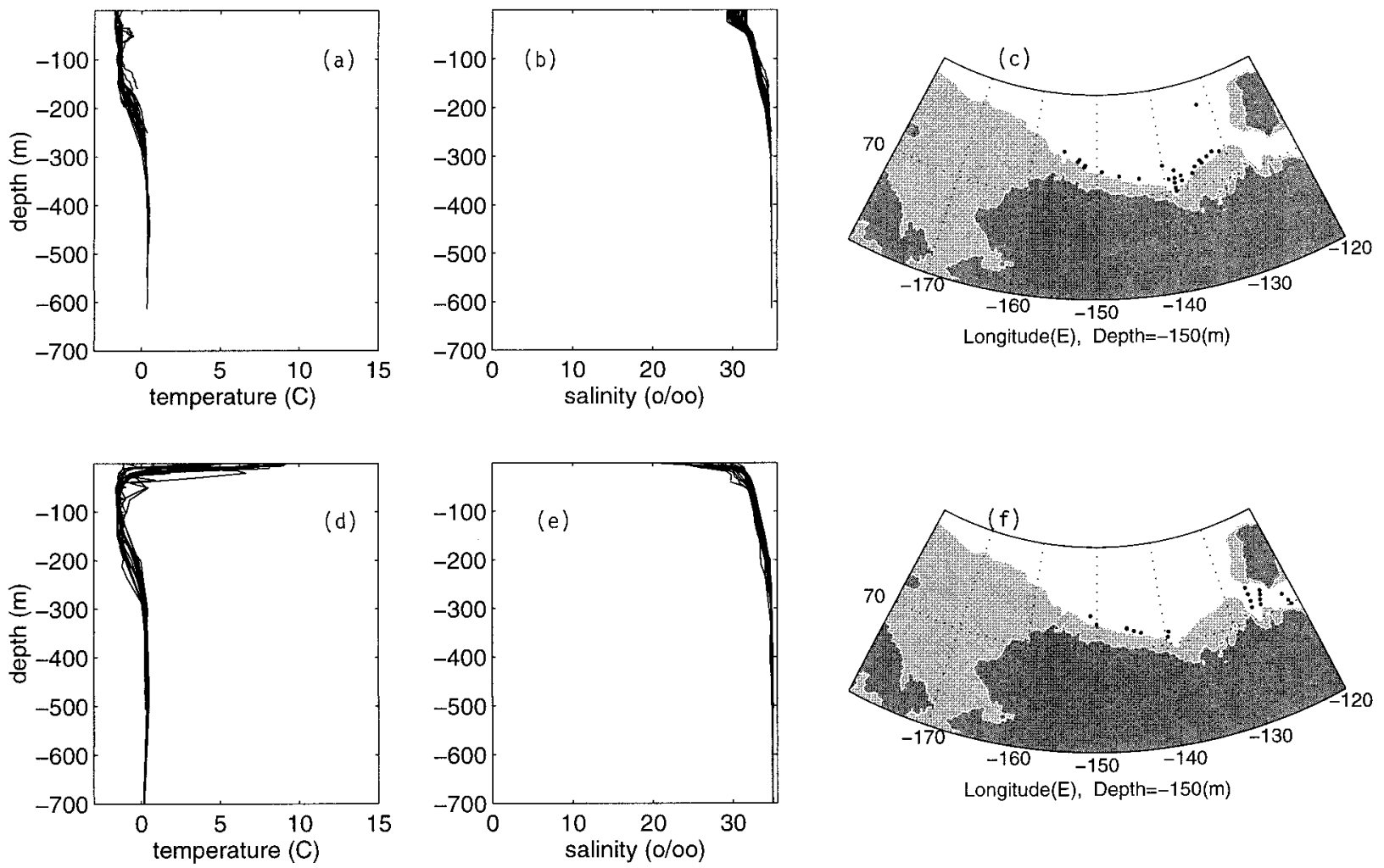

FIG. 4. Seasonal variation of $T, S$ profiles over the Beaufort/Chukchi Sea deep water: (a) winter (Nov-Apr) $T$ profiles, (b) winter $S$ profiles, (c) distribution of winter stations, (d) summer (Aug) $T$ profiles, (e) summer $S$ profiles, and (f) distribution of summer stations. The shaded areas indicate shelf region (water depth $\leq 150 \mathrm{~m}$ ).

depth to a maximum value $T_{\max }$ and then monotonic decreasing with depth), is generated by a prominent hydrographic feature on the Beaufort Sea shelf: a subsurface temperature maximum, generally found at about 20-30-m depth in the deep water and at about $10-\mathrm{m}$ depth in the shelf water. This temperature maximum is associated with the eastward-flowing Bering Sea water (Coachman and Barnes 1961; Aagaard 1984). The warm water that enters the Beaufort Sea comes through the eastern Bering Strait and follows the Alaskan coast around Point Barrow. Mountain et al. (1976) identified this warm intrusion as the combination of the two water masses: warm $\left(5^{\circ}-10^{\circ} \mathrm{C}\right)$ and fresh (salinity below 31.5 psu) Alaskan Coastal Water (ACW), and the more saline Bering Sea Water (BSW). The two water masses mix rapidly with the ambient surface water as they move eastward. Aagaard (1984) estimated that ACW is not clearly identifiable east of $147^{\circ}-148^{\circ} \mathrm{W}$, and BSW east of $143^{\circ} \mathrm{W}$. Thus, in this study we choose the longitude of $141^{\circ} \mathrm{W}$ as a separation for the western and eastern parts of the Beaufort Sea shelf water.

\section{c. Occurrence of various types on continental shelf}

The Beaufort/Chukchi Sea shelf water demonstrates a strong seasonal variation. During winter (NovemberApril), most temperature and salinity profiles are of the
DM type (Figs. 3a,b, and 5a). During summer (August), temperature and salinity profiles (Figs. 3d,e) indicate multilayer structure, that is, SM-type $T, S$ profiles and AD-type $T$ profiles. To further illustrate the spatial variation of the thermohaline structure, we divided the shelf region into three parts (Fig. 7): (a) southern Chukchi Sea $\left(65^{\circ}-70^{\circ} \mathrm{N}, 160^{\circ} \mathrm{W}-180^{\circ}\right)$; (b) northern Chukchi/ western Beaufort Sea shelf $\left(70^{\circ}-75^{\circ} \mathrm{N}, 141^{\circ} \mathrm{W}-180^{\circ}\right)$; and (c) eastern Beaufort Sea shelf $\left(68^{\circ}-75^{\circ} \mathrm{N}, 120^{\circ}-\right.$ $\left.141^{\circ} \mathrm{W}\right)$. The relative number of summer profiles in each of the categories is listed in Tables 1 and 2 .

In August, as expected, the DM type of $T$ profiles exhibit less occurrence (23\% in total region, only $1 \%$ in the eastern Beaufort shelf) than the SM type of $T$ profiles (Table 1). The number of SM-type profiles is much more than the AD-type profiles. Most AD-type $T$ profiles (174) appear in the northern Chukchi/western Beaufort shelf, where the Bering Sea water intrusion appears to flow over the broad shelf poleward into deeper water.

In August, the DM type of $S$ profiles (Table 2) is less prevalent than the SM type in the northern Chukchi/ western Beaufort Sea shelf (DM type: 19\%; SM type: $81 \%$ ) and in the eastern Beaufort Sea shelf (DM type: 8\%; SM type: $92 \%$ ). However, the DM type dominates the southern Chukchi Sea (DM type: 77\%; SM type: 


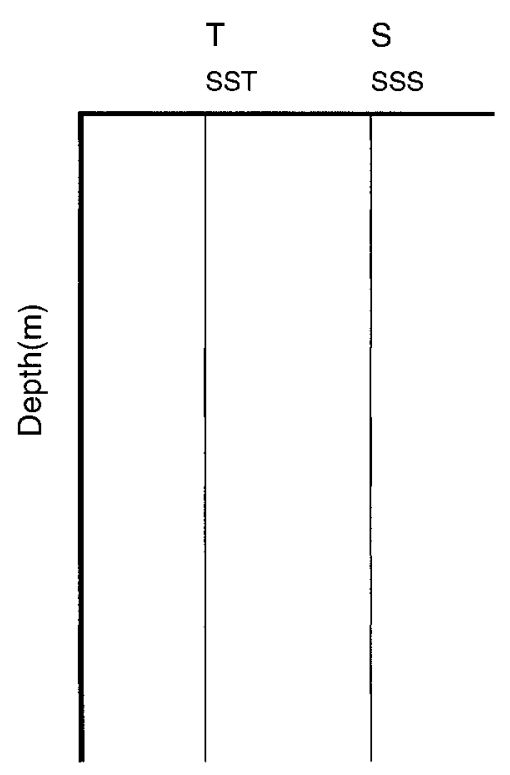

(a)

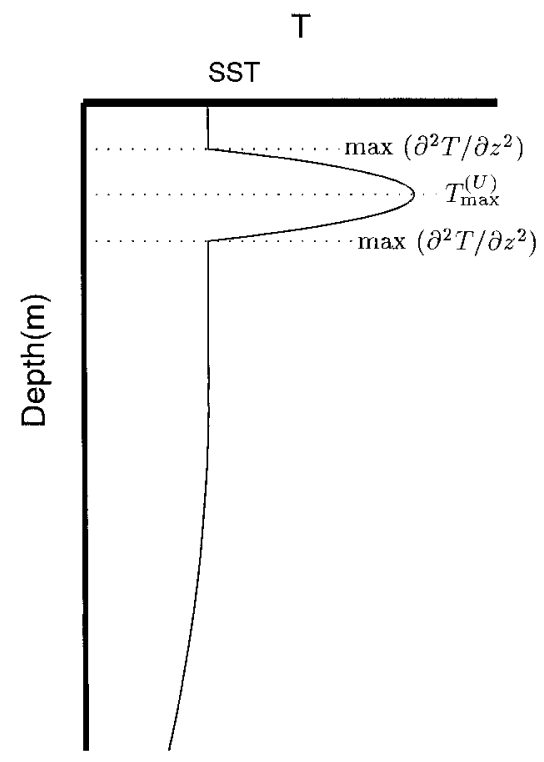

(c)

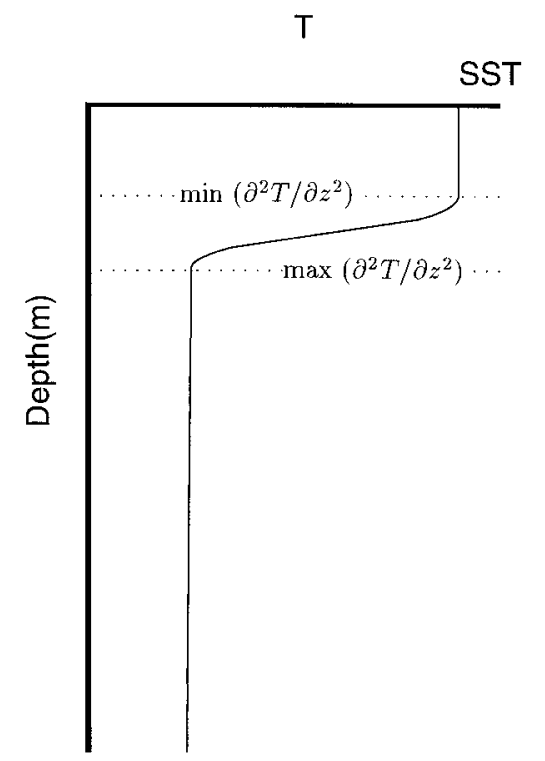

(b)

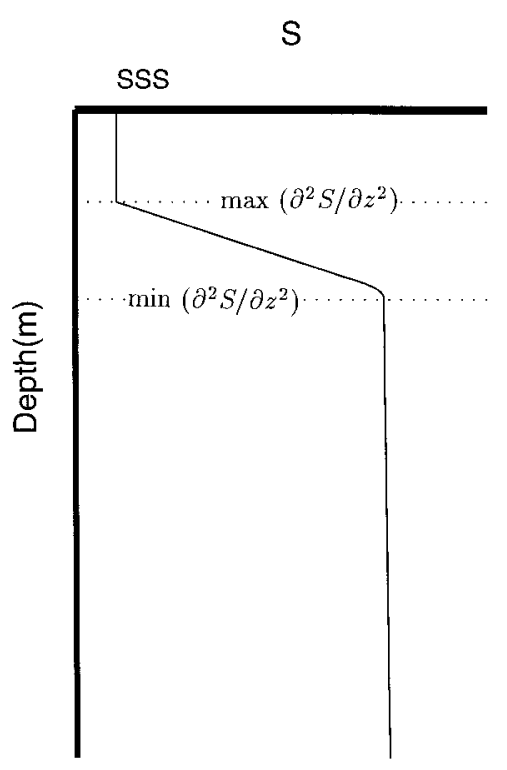

(d)

FIG. 5. Typical $T, S$ profiles for the shelf water: (a) DM-type $T, S$; (b) SM-type $T$; (c) AD-type $T$; and (d) SM-type $S$.

23\%). The DM-type occurrence decreases from the southern Chukchi Sea to the northern Chukchi/West Beaufort Sea shelf, and further reduces toward the eastern Beaufort Sea shelf.

\section{d. Occurrence of various types in deep water}

The Beaufort Sea deep water also experiences a seasonal variation, but not as strong as the shelf water. Most winter (December-April) historical (1970-93) data show DM-type temperature profiles (Table 3). On the other hand, all three types of $T$ profiles are present in the August historical (1970-93) temperature data (Table 3 ). Among them, the DM type accounts for $45 \%$, the SM type for $39 \%$, and the AD type for $16 \%$. Regardless of season, the salinity generally exhibits an SM-type profile, that is, nearly isohaline with a weak, near-surface gradient sometimes present. 
$\mathrm{T}$

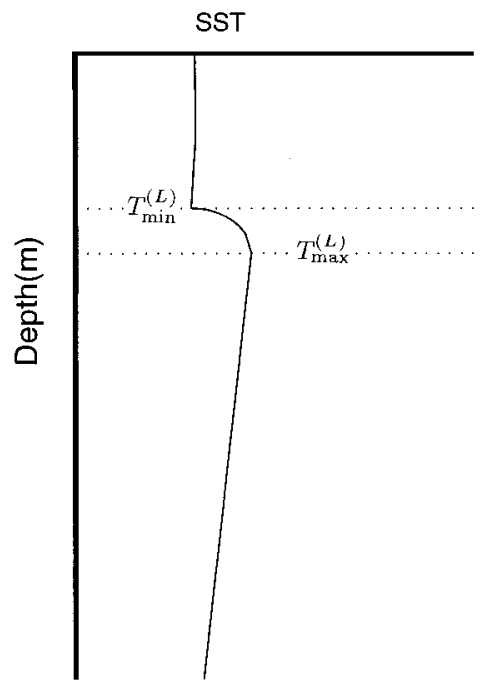

(a)

$\mathrm{T}$

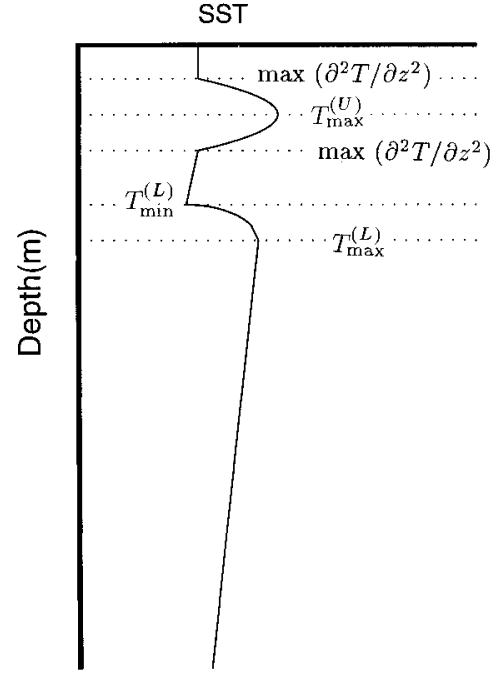

(c)
$T$

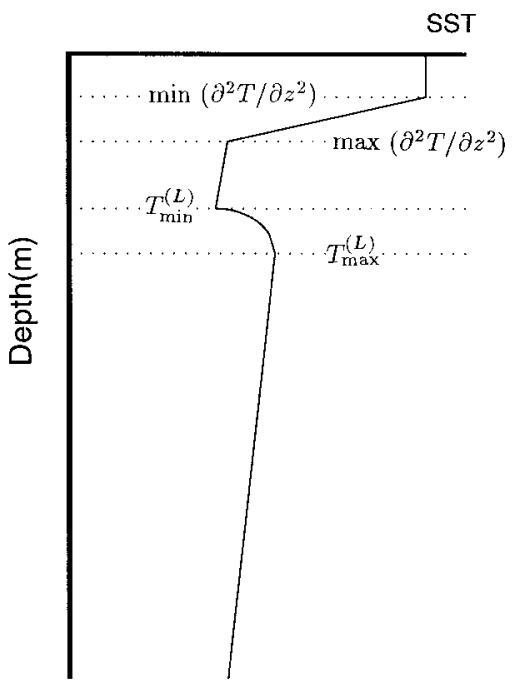

(b)

$\mathrm{S}$

SSS

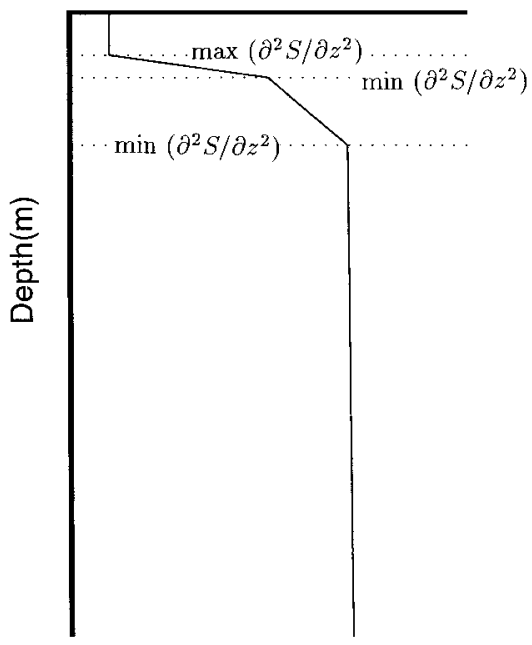

(d)

T and S Typical Profiles in Deep Water

FIG. 6. Typical $T, S$ profiles for the deep water: (a) DM-type $T$, $S$; (b) SM-type $T$; (c) AD-type $T$; and (d) SM-type $S$.

\section{Geometric features of $T, S$ profiles}

Second derivatives $\partial^{2} F\left(z_{i}\right) / \partial z^{2}(F$ is $T$ or $S$ ) are used below to describe the geometric features of profiles and to identify various types of $T, S$ profiles in the Beaufort and Chukchi Seas.

\section{a. Nonhomogeneous mesh difference scheme}

For each profile (temperature or salinity), $F\left(z_{i}\right), i=$ $1,2, \ldots, N$, we use the following nonhomogeneous mesh difference scheme for the second-order derivatives:

$$
\left.\frac{\partial^{2} F}{\partial z^{2}}\right|_{z_{i}} \simeq \frac{1}{z_{i+1}-z_{i-1}}\left(\frac{F_{i+1}-F_{i}}{z_{i+1}-z_{i}}-\frac{F_{i}-F_{i-1}}{z_{i}-z_{i-1}}\right) .
$$

Here, $i=1$ refers to the surface, with increasing values indicating downward extension of the measurement. Equation (1) shows that we need two neighboring values, $F_{i-1}$ and $F_{i+1}$, to compute the second-order deriv- 


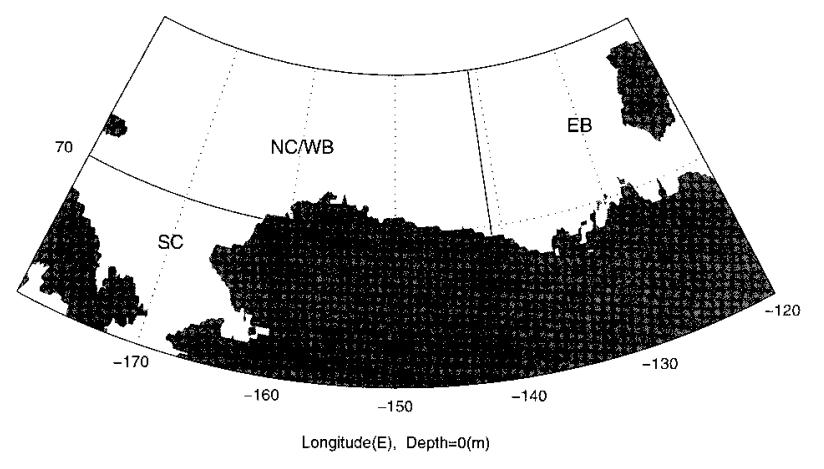

FIG. 7. Division of Beaufort/Chukchi Sea.

ative at $z_{i}$. For $i=1, N$, we use the next point value, that is,

$$
\left.\frac{\partial^{2} F}{\partial z^{2}}\right|_{z_{1}}=\left.\frac{\partial^{2} F}{\partial z^{2}}\right|_{z_{2}},\left.\quad \frac{\partial^{2} F}{\partial z^{2}}\right|_{z_{N}}=\left.\frac{\partial^{2} F}{\partial z^{2}}\right|_{z_{N}-1} .
$$

After the second-order difference is computed, we can use the following model to determine the top and bottom of the upper thermocline and halocline.

The mixed layer depth has a large variability, ranging from few meters to tens of meters. To resolve the mixed layer depth from $T, S$ profiles, we have to use $T, S$ values one depth increment above and below for computing the second derivatives. This is due to that the finest vertical resolution is $1 \mathrm{~m}$ in our dataset (CTD data).

\section{b. Features of the shelf water profiles}

As stated previously, there are three types of $T$ profiles (DM, SM, and AD types) and two types of $S$ profiles (DM and SM types) found in the shelf water. The DMtype $T, S$ profiles reveal a single-layer structure (Fig. $5 \mathrm{a})$; that is, the surface mixed layer extends to the bottom of the shelf (vertically uniform).

The SM-type $T$ profiles are characterized by a minimum (maximum) of $\partial^{2} T / \partial z^{2}$ at top (bottom) of the thermocline. Thus, the depths of the first minimum and the first maximum of $\partial^{2} T / \partial z^{2}$ are taken as the top, $d_{1}^{T}$, and bottom, $d_{2}^{T}$, of the thermocline (Fig. 5b), respectively.

The AD-type $T$ profiles are depicted by maxima of $\partial^{2} T / \partial z^{2}$ at both top of the upper thermocline and bottom of the lower thermocline and a depth, $d_{\max }^{T}$, with the maximum temperature $T_{\max }^{U}$. The depths of the first and

TABLE 1. Number of continental shelf temperature profiles in Aug.

\begin{tabular}{lcccc}
\hline \hline \multicolumn{1}{c}{ Area } & DM type & SM type & AD type & Total \\
\hline SC shelf & 93 & 228 & 14 & 335 \\
NC/WB shelf & 140 & 228 & 174 & 542 \\
EB shelf & 2 & 128 & 1 & 131 \\
Total & 235 & 584 & 189 & 1008 \\
\hline
\end{tabular}

TABLE 2. Number of continental shelf salinity profiles in Aug.

\begin{tabular}{lccc}
\hline \hline \multicolumn{1}{c}{ Area } & DM type & SM type & Total \\
\hline SC shelf & 205 & 61 & 266 \\
NC/WB shelf & 87 & 363 & 450 \\
EB shelf & 9 & 100 & 109 \\
Total & 311 & 524 & 825 \\
\hline
\end{tabular}

second maxima of $\partial^{2} T / \partial z^{2}$ are taken as top $d_{1}^{T}$ and bottom $d_{2}^{T}$ of the upper and lower thermoclines (Fig. 5c).

The SM-type $S$ profiles are featured by a maximum (minimum) of $\partial^{2} S / \partial z^{2}$ at top (bottom) of the halocline. From the ocean surface downward, the depths of the first maximum and the first minimum of $\partial^{2} S / \partial z^{2}$ are taken as top $d_{1}^{S}$ and bottom $d_{2}^{S}$ of the halocline for SMtype $S$ profiles (Fig. $5 \mathrm{~d}$ ).

\section{c. Features of the deep water profiles}

There are three types of $T$ profiles (DM, SM, and AD types) and only one type of $S$ profile (SM type) in the deep water regime.

The DM-type $T$ profiles reveal a thick surface mixed layer (Fig. 6a) above a positive gradient thermocline. The SM-type $T$-profiles are characterized by a minimum (maximum) of $\partial^{2} T / \partial z^{2}$ at top (bottom) of the upper thermocline. Thus, the depths of the first minimum and the first maximum of $\partial^{2} T / \partial z^{2}$ are taken as top $d_{1}^{T}$ and bottom $d_{2}^{T}$ of the upper thermocline (Fig. 6b). Below the upper thermocline, a region of cold, nearly isothermal water exists, which is a remnant of the previous water's cooling and convective mixing. Beneath this isothermal layer, is a positive gradient lower thermocline similar to that of the DM type.

The AD-type $T$ profiles are depicted by maxima of $\partial^{2} T / \partial z^{2}$ at both top and bottom of the upper and lower thermoclines and a depth, $d_{\max }^{T}$, with a maximum temperature, $T_{\max }^{U}$. The depths of the first and second maxima of $\partial^{2} T / \partial z^{2}$ are taken as top $d_{1}^{T}$ and bottom $d_{2}^{T}$ of the upper thermocline (Fig. 6c). Below the depth of intrusion of warm Bering Sea water, the temperature profile is similar to that described by the DM profiles.

The SM-type $S$ profile is characterized by a maximum (minimum) of $\partial^{2} S / \partial z^{2}$ at top (bottom) of the upper halocline. From the ocean surface downward, the depths of the first maximum and the first minimum of $\partial^{2} S / \partial z^{2}$ are taken as the top $d_{1}^{S}$ and bottom $d_{2}^{S}$ of the upper halocline (Fig. 6d). A lower halocline, when present, is often concurrent with the positive thermocline of the SM-type $T$ profile and is characterized by a minimum of $\partial^{2} S / \partial z^{2}$ at the lower halocline.

TABLE 3. Seasonal variation of number of deep water temperature profiles.

\begin{tabular}{lcccc}
\hline \hline Months & DM type & SM type & AD type & Total \\
\hline Nov-Apr & 23 & 0 & 3 & 26 \\
Aug & 28 & 24 & 10 & 62 \\
\hline
\end{tabular}




\section{d. Surface mixed layer}

The bottom of the mixed layer is approximately the same as the top of the upper thermocline (or halocline). The mixed layer has a depth of $d_{1}^{F}$, that is,

$$
\operatorname{MLD}^{F}=d_{1}^{F} \text {. }
$$

When $d_{1}^{F}$ tends to an infinitesimally small depth $\left(d_{1}^{F}\right.$ $\simeq 0$ ), that is, the upper thermocline (halocline) reaches the surface, the surface mixed layer disappears. We call such profiles stratified and treat them as a special case of the ordinary SM-type or AD-type profiles when $d_{1}^{F}$ is extremely small.

\section{e. Lower thermocline}

The lower thermocline appears in the Beaufort Sea deep water. The major geometric feature of $T$ profiles is the existence of minimum and maximum temperatures below the upper thermocline for the SM-type and ADtype profiles (Figs. 6b,c),

$$
\begin{aligned}
T_{\min } & =\min _{z<-d_{2}^{T}} T(z) \quad \text { and } \quad T_{\max }=\max _{z<-d_{2}^{T}} T(z), \\
d_{3}^{T} & =-\left\{z \mid T(z)=T_{\min }\right\}, \\
d_{4}^{T} & =-\left\{z \mid T(z)=T_{\max }\right\},
\end{aligned}
$$

where $d_{3}^{T}$ and $d_{4}^{T}$ are the depths of the minimum and maximum temperatures below the upper thermocline and the corresponding data are $T\left(-d_{3}^{T}\right)$ and $T\left(-d_{4}^{T}\right)$. We may identify the layer between $d_{3}^{T}$ and $d_{4}^{T}$ as the lower thermocline. Usually, between the upper and lower thermoclines there is a transition zone with a very weak vertical gradient.

\section{Thermohaline geometric model}

Let $T$ and $S$ be represented by $F$. After the four depths $d_{1}^{F}, d_{2}^{F}, d_{3}^{F}$, and $d_{4}^{F}$ are determined from temperature and salinity profiles, we may obtain some important physical parameters from each profile.

\section{a. Mixed layer}

The water above the depth of $d_{1}^{F}$ is taken as the mixed layer. Within the mixed layer, the temperature (salinity) is assumed to be uniform with depth; that is, the mixed layer temperature is the same as the sea surface temperature:

$$
\hat{F}(z)=F(0), \quad-d_{1}^{F}<z \leq 0 \text { (mixed layer). }
$$

\section{b. Entrainment zone}

The entrainment zone below the mixed layer is assumed to be infinitesimally thin near the depth of $d_{1}^{F}$. The temperature (salinity) at the top of the entrainment zone is the same as the mixed layer temperature, and the temperature (salinity) at the bottom of the entrainment zone equals the temperature (salinity) at the top of the thermocline. Therefore, the temperature and salinity jump across the entrainment zone is represented as

$$
\Delta F=F(0)-F\left(-d_{1}^{F}\right), \quad F=T, S .
$$

\section{c. Upper thermocline and halocline}

The upper thermocline and halocline are located between $z=-d_{1}^{F}$ and $z=-d_{2}^{F}$. Vertical gradients of the upper thermocline $\left(G_{\mathrm{th}}^{U}\right)$ and halocline $\left(G_{\text {ha }}^{U}\right)$ for SM-type $T, S$ profiles are

$$
\begin{aligned}
G_{\mathrm{th}}^{U} & =\frac{T\left(-d_{1}^{T}\right)-T\left(-d_{2}^{T}\right)}{d_{2}^{T}-d_{1}^{T}} \text { and } \\
G_{\mathrm{ha}}^{U} & =\frac{S\left(-d_{1}^{S}\right)-S\left(-d_{2}^{S}\right)}{d_{2}^{S}-d_{1}^{S}} .
\end{aligned}
$$

The vertical gradient of the upper thermocline $\left(G_{\mathrm{th}}^{U}\right)$ for AD-type $T$ profiles is estimated by

$$
G_{\mathrm{th}}^{U}=\frac{1}{2}\left[\frac{\left|T\left(-d_{1}^{T}\right)-T\left(-d_{\max }^{T}\right)\right|}{d_{\max }^{T}-d_{1}^{T}}+\frac{\left|T\left(-d_{\max }^{T}\right)-T\left(-d_{2}^{T}\right)\right|}{d_{2}^{T}-d_{\max }^{T}}\right] .
$$

\section{d. Lower thermocline and halocline}

The lower thermocline and halocline are located between $z=-d_{3}^{F}$ and $z=-d_{4}^{F}$. Vertical gradients of the lower thermocline $\left(G_{\mathrm{th}}^{L}\right)$ and halocline $\left(G_{\mathrm{ha}}^{L}\right)$ are estimated by

$$
\begin{aligned}
G_{\mathrm{th}}^{L} & =\frac{T\left(-d_{3}^{T}\right)-T\left(-d_{4}^{T}\right)}{d_{4}^{T}-d_{3}^{T}} \text { and } \\
G_{\mathrm{ha}}^{L} & =\frac{S\left(-d_{3}^{S}\right)-S\left(-d_{4}^{S}\right)}{d_{4}^{S}-d_{3}^{S}} .
\end{aligned}
$$

\section{Model evaluation}

\section{a. Model profile}

The thermohaline parametric model turns any profile into physical parameters: four depths $\left(d_{1}^{F}, d_{2}^{F}, d_{3}^{F}, d_{4}^{F}\right)$, temperature or salinity jump $\Delta F$, and upper and lower thermocline (halocline) strength. Taking SM-type $T, S$ profiles as an example (remember that the DM type is a special case of the SM type), we construct a modeled profile $\hat{F}\left(z_{i}\right)$, to evaluate the performance of the thermohaline parametric model: 


$$
\begin{array}{ll}
\hat{F}(z)=F(0), & -d_{1}^{F}<z \leq 0, \\
\hat{F}(z)=F\left(-d_{1}^{F}\right)-\frac{z+d_{1}^{F}}{d_{2}^{F}-d_{1}^{F}}\left[F\left(-d_{2}^{F}\right)-F\left(-d_{1}^{F}\right)\right], & -d_{2}^{F} \leq z \leq-d_{1}^{F}, \\
\hat{F}(z)=F\left(-d_{2}^{F}\right)-\frac{z+d_{2}^{F}}{d_{3}^{F}-d_{2}^{F}}\left[F\left(-d_{3}^{F}\right)-F\left(-d_{2}^{F}\right)\right], & -d_{3}^{F} \leq z \leq-d_{2}^{F}, \\
\hat{F}(z)=F\left(-d_{3}^{F}\right)-\frac{z+d_{3}^{F}}{d_{4}^{F}-d_{3}^{F}}\left[F\left(-d_{4}^{F}\right)-F\left(-d_{3}^{F}\right)\right], & -d_{4}^{F} \leq z \leq-d_{3}^{F},
\end{array}
$$

and

$$
\hat{F}(z)=F\left(-d_{4}^{F}\right)-\frac{z+d_{4}^{F}}{d_{N}^{F}-d_{4}^{F}}\left[F\left(-d_{N}^{F}\right)-F\left(-d_{4}^{F}\right)\right], \quad-d_{N}^{F} \leq z \leq-d_{4}^{F},
$$

which is vertically uniform in the mixed layer and piecewise linear with depth below the mixed layer to the deepest depth of the observational point $z=-d_{N}^{F}$. Notice that the "model profile" takes the value of $F\left(-d_{1}^{F}\right)$ at the mixed layer base $z=-d_{1}^{F}$.

AD-type profiles can also be represented by (11) except for the upper thermocline $\left(-d_{2}^{T} \leq z \leq-d_{1}^{T}\right)$, which should be parameterized by

$$
\begin{gathered}
\hat{T}(z)=T\left(-d_{1}^{F}\right)-\frac{z+d_{1}^{T}}{d_{\max }^{T}-d_{1}^{T}}\left[T\left(-d_{\max }^{T}\right)-T\left(-d_{1}^{T}\right)\right], \\
-d_{\max }^{T} \leq z \leq-d_{1}^{T},
\end{gathered}
$$

and

$$
\begin{gathered}
\hat{T}(z)=T\left(-d_{\max }^{T}\right)-\frac{z+d_{\max }^{T}}{d_{2}^{T}-d_{\max }^{T}}\left[T\left(-d_{2}^{T}\right)-T\left(-d_{\max }^{T}\right)\right], \\
-d_{2}^{T} \leq z \leq-d_{\max }^{T},
\end{gathered}
$$

where $T\left(-d_{\max }^{F}\right)=T_{\max }^{U}$.

\section{b. Root-mean-square error}

The model performance can be evaluated by the rootmean-square error (rmse),

$$
\operatorname{rmse}_{m}=\sqrt{\frac{1}{N} \sum_{i=0}^{N}\left[\hat{F}_{m}\left(z_{i}\right)-F_{m}\left(z_{i}\right)\right]^{2}},
$$

where the subscript $m$ indicates the $m$ th profile $\hat{F}_{m}(z)$. When we consider a group of profiles, we may compute the mean value,

$$
\text { rmse }=\frac{1}{M} \sum_{m=1}^{M} \mathrm{rmse}_{m},
$$

where $M$ is total number of profiles. If the model is perfect, $\hat{F}_{m}\left(z_{i}\right)=F_{m}\left(z_{i}\right)$. The rmse $_{m}$ should be zero. Usually, the model is not perfect. The smaller the rmse, the better the performance of the model.

\section{c. Statistical tests}

For any profile, $F\left(z_{i}\right),=1,2, \ldots, N$, using (11), and/or (11) and (12), we obtain a corresponding model profile, $\hat{F}\left(z_{i}\right), i=1,2, \ldots, N$. Both $F(z)$ and $\hat{F}(z)$ have the same values at the depths $0,-d_{1}^{F},-d_{2}^{F},-d_{3}^{F},-d_{4}^{F}$, and $-d_{N}^{F}$, but do not necessarily have the same values at the other observational depths. If $\hat{F}(z)$ fits $F(z)$ well, the difference $\delta F\left(z_{i}\right)=F\left(z_{i}\right)-\hat{F}\left(z_{i}\right)$ should be very small at all observational points. We need to test if the difference is small enough to be neglected. The first test (paired data test) is used to justify whether the mean value of $\delta F\left(z_{i}\right)$ is taken as zero. The second test (correlation test) is utilized to see whether $\hat{F}(z)$ correlates well with $F(z)$.

\section{1) PAired data Test ( $t$ Test)}

After calculating the mean and standard deviation of $\delta F\left(z_{i}\right)$,

$$
\begin{aligned}
\overline{\delta F} & =\frac{1}{N} \sum_{i=1}^{N} \delta F\left(z_{i}\right), \\
s_{\delta F}^{2} & =\frac{1}{(N-1)} \sum_{i=1}^{N}\left[\delta F\left(z_{i}\right)-\overline{\delta F}\right]^{2} .
\end{aligned}
$$

we begin with the null hypothesis that $\overline{\delta F}$ is zero. The significance level $(\alpha=0.001)$ is the probability that the given value of

$$
t=\frac{\overline{\delta F}}{s_{\delta F} / \sqrt{N}}
$$

is exceeded purely by chance. This value satisfies the $t$ distribution with $N-1$ degrees of freedom. If $|t|>$ $t_{\alpha, N-1}$, we reject the null hypothesis, and the modeled profile $\hat{F}(z)$ does not fit the observation $F(z)$ and should be rejected.

\section{2) CoRrelation test ( $F$-TEST)}

After a modeled profile $\hat{F}(z)$ passes the paired data test, we start with the null hypothesis that $\hat{F}(z)$ does not 
TABLE 4. Number of fitted profiles and rmse before and after the $t$ and $F$-tests.

\begin{tabular}{|c|c|c|c|c|c|c|c|}
\hline & & \multirow{2}{*}{\multicolumn{2}{|c|}{$\begin{array}{c}\text { Shelf water } \\
\text { Summer }\end{array}$}} & \multicolumn{4}{|c|}{ Deep water } \\
\hline & & & & \multicolumn{2}{|c|}{ Summer } & \multicolumn{2}{|c|}{ Winter } \\
\hline & & KK & rmse & KK & rmse & $\mathrm{KK}$ & rmse \\
\hline \multicolumn{8}{|l|}{$T$} \\
\hline & Before & 1027 & 0.25 & 62 & 0.31 & 26 & 0.14 \\
\hline & After & 850 & 0.18 & 61 & 0.3 & 21 & 0.12 \\
\hline \multicolumn{8}{|l|}{$S$} \\
\hline & Before & 788 & 0.24 & 19 & 0.22 & 24 & 0.17 \\
\hline & After & 580 & 0.16 & 19 & 0.22 & 18 & 0.14 \\
\hline
\end{tabular}

correlate with the observation $F(z)$. The significance level $(\alpha=0.05)$ is the probability that the given value of

$$
f=\frac{\sum_{i=1}^{N}\left[\hat{F}\left(z_{i}\right)-\overline{\hat{F}}\right]^{2}}{\sum_{i=0}^{N}\left[\hat{F}\left(z_{i}\right)-F\left(z_{i}\right)\right]^{2} /(N-2)}
$$

is not exceeded purely by chance. This value satisfies the $F$ distribution with $(1, N-2)$ degrees of freedom. If $f>F_{\alpha}(1, N-2)$, we reject the null hypothesis and conclude that the modeled profile $\hat{F}(z)$ does correlate with the observation $F(z)$.

\section{Model-data comparison}

\section{a. Overall performance}

Any profile that passes both the $t$-test and the $F$-test is termed a fitted profile. The more fitted profiles that exist, the more representative they are of the geometric model. Taking all the August profiles as an example, almost all the deep water profiles are fitted profiles, but only about $80 \%$ of the shelf profiles are fitted profiles (Table 4). After the two tests, the rmse of the shelf profiles has drastic reductions: $0.25^{\circ}-0.18^{\circ} \mathrm{C}$ and $0.24-$ 0.16 psu (Table 4). We checked those shelf profiles that did not fit the model (around 20\%) and found that the most of them had a very poor vertical resolution. It was hard for the geometric model to fit those profiles.

\section{b. Shelf water}

During winter (November-April) most $T, S$ profiles exhibit a single-layer structure (DM-type profiles). It therefore was not necessary to use the geometric model to parameterize those profiles.

During summer (August) $T, S$ profiles have a multilayer structure. Figure 8 shows the model performance of the SM-type $T, S$ profiles for the three shelf regions: (a) southern Chukchi (SC) Sea, (b) northern Chukchi/ western Beaufort (NC/WB) Sea, and (c) eastern Beaufort (EB) Sea. After application of the $t$ - and $F$-tests, the mean rmse of temperature is $0.14^{\circ} \mathrm{C}$ for $\mathrm{SC}, 0.19^{\circ} \mathrm{C}$ for $\mathrm{NC} / \mathrm{WB}$, and $0.29^{\circ} \mathrm{C}$ for $\mathrm{EB}$ (Table 5). The mean rmse of salinity is 0.07 psu for SC, 0.20 psu for $\mathrm{NC} /$ WB, and 0.29 psu for EB (Table 6). Figure 9 shows the model performance of the AD-type $T$ profiles for the $\mathrm{NC} / \mathrm{WB}$ shelf region. After applying the $t$ - and $F$-tests, the mean rmse of temperature is $0.3^{\circ} \mathrm{C}$ for NC/WB (Table 5).

\section{c. Deep water}

The deep water exhibits a multilayer structure all year round. Comparison between the observed and modeled profiles (Fig. 10) shows that the geometric model parameterizes the various type profiles reasonably well. The rmse of the winter $T$ profiles is $0.12^{\circ} \mathrm{C}$. The rmse of the summer $T$ profiles is $0.25^{\circ} \mathrm{C}$ for the DM-type profiles, $0.28^{\circ} \mathrm{C}$ for the SM-type profiles, and $0.45^{\circ} \mathrm{C}$ for the AD-type profiles (Table 5). The rmse of the $S$ profiles is 0.14 psu for the winter profiles and 0.22 for the summer profiles (Table 6).

The upper portion of the Beaufort/Chukchi Sea deep water experiences a seasonal variation. During the winter season (November-April), the surface temperature mixed layer is much deeper than the surface salinity mixed layer (Fig. 10): $\operatorname{MLD}^{(T)} \simeq 170 \mathrm{~m}, \mathrm{MLD}^{(S)} \simeq 30$ $\mathrm{m}$. During other seasons (May-October), the surface mixed layer may shoal. August $T$ profiles show the existence of two types of thermohaline structures: (a) deep mixing (Fig. 10e) and (b) shallow mixing (Fig. 10g) and only one type (shallow mixing) for the salinity (Fig. $10 \mathrm{i})$.

\section{Beaufort/Chukchi Sea thermohaline features}

The thermohaline geometric model turns each temperature (or salinity) profile into a set of physical parameters. During the winter the water throughout the Beaufort/Chukchi Sea shelf regions is quite uniform in the vertical. As the summer approaches, an increase in the solar insolation begins the stratification process and causes a more complicated multilayer thermohaline structure in the Beaufort/Chukchi Sea shelf. Therefore, we choose August profiles as examples for illustrating the usefulness of the geometric model.

\section{a. SST and SSS}

Seasonal evolution of SST (Fig. 11) constructed from the MOODS data (1970-93), shows some interesting features. Due to data sparseness, we show only the horizontal distribution of warm water $\left(\mathrm{SST}>0^{\circ} \mathrm{C}\right)$ and cold water $\left(\mathrm{SST} \leq 0^{\circ} \mathrm{C}\right)$. During the winter season (November-April), radiative cooling makes the whole Beaufort/Chukchi SST fall below $0^{\circ} \mathrm{C}$ (Fig. 11a). During the spring season (May-July) warm water appears in the southern Chukchi Sea (Fig. 11b), this is caused by gradual increase of the solar radiation and the advected warm water through the eastern Bering Strait. During summer season (August), SST of the deep water is still 

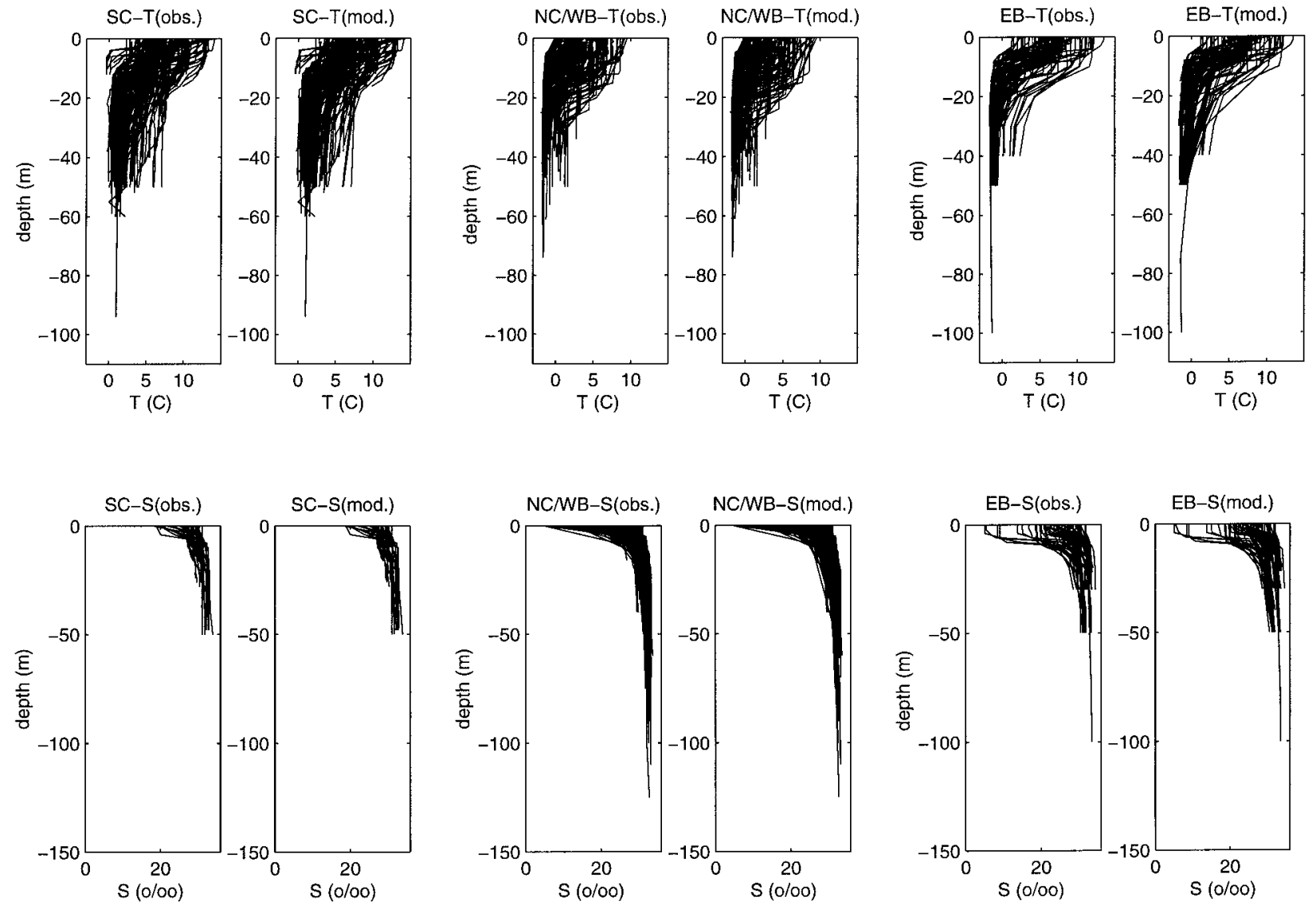

FIG. 8. August SM-type observed $T, S$ profiles and corresponding modeled profiles for the shelf water: (a) observed SC temperature, (b) modeled SC temperature, (c) observed NC/WB temperature, (d) modeled NC/WB temperature, (e) observed EB temperature, (f) modeled EB temperature, (g) observed SC salinity, (h) modeled SC salinity, (i) observed NC/WB salinity, (j) modeled NC/WB salinity, (k) observed EB salinity, and (l) modeled EB salinity.

cold (below $0^{\circ} \mathrm{C}$ ), and still quite cold in the northern Chukchi/western Beaufort Sea (Figs. 11c,d,e). However, SST of the shelf water is warm (above $0^{\circ} \mathrm{C}$ ) in both southern Chukchi Sea and eastern Beaufort Sea. During the fall season (October), the cold SST almost occupies the whole Beaufort Sea. However, the southern Chukchi Sea is still warm (Fig. 11f).

Similar to the SST fields, we show the seasonal and horizontal variations of salty and freshwater (Fig. 12). The criterion for separating the salty and freshwater is 31.5 psu during November-June, and 26 psu during July-October.

Figures 11 and 12 clearly show the intrusion of the warm salty Bering Sea water into the Chukchi Sea and

TABle 5. The rmse of temperature profiles $\left({ }^{\circ} \mathrm{C}\right)$.

\begin{tabular}{lcccc}
\hline \hline \multicolumn{1}{c}{ Area } & $\begin{array}{c}\text { DM } \\
\text { (winter) }\end{array}$ & $\begin{array}{c}\text { DM } \\
\text { (summer) }\end{array}$ & $\begin{array}{c}\text { SM } \\
\text { (summer) }\end{array}$ & $\begin{array}{c}\text { AD } \\
\text { (summer) }\end{array}$ \\
\hline SC shelf & - & - & 0.14 & - \\
NC/WB shelf & - & - & 0.19 & 0.30 \\
EB shelf & - & - & 0.29 & - \\
Deep water & 0.12 & 0.25 & 0.28 & 0.45 \\
\hline
\end{tabular}

Beaufort Sea especially from May to October. This influx was discussed by Mountain et al. (1976), Paquette and Bourke (1974), and others. Besides, our results also show strong mixing of the warm salty Bering Sea water mass with the cold fresh Beaufort Sea water during winter season (November-April).

\section{b. Summer (August) shelf water thermohaline structure}

\section{1) Southern Chukchi Sea Shelf}

Figure 13 exhibits the histograms of the subsurface parameters $\left[\mathrm{MLD}^{T}, \Delta T,\left(d_{2}^{T}-d_{1}^{T}\right), G_{\mathrm{th}}, \mathrm{MLD}^{S}, \Delta S\right.$,

\section{TABLE 6. The rmse of salinity profiles (psu).}

\begin{tabular}{lccc}
\hline \hline \multicolumn{1}{c}{ Area } & $\begin{array}{c}\text { DM } \\
\text { (winter) }\end{array}$ & $\begin{array}{c}\text { DM } \\
\text { (summer) }\end{array}$ & $\begin{array}{c}\text { SM } \\
\text { (summer) }\end{array}$ \\
\hline SC shelf & - & - & 0.07 \\
NC/WB shelf & - & - & 0.20 \\
EB shelf & - & - & 0.29 \\
Deep water & 0.14 & - & 0.22 \\
\hline
\end{tabular}



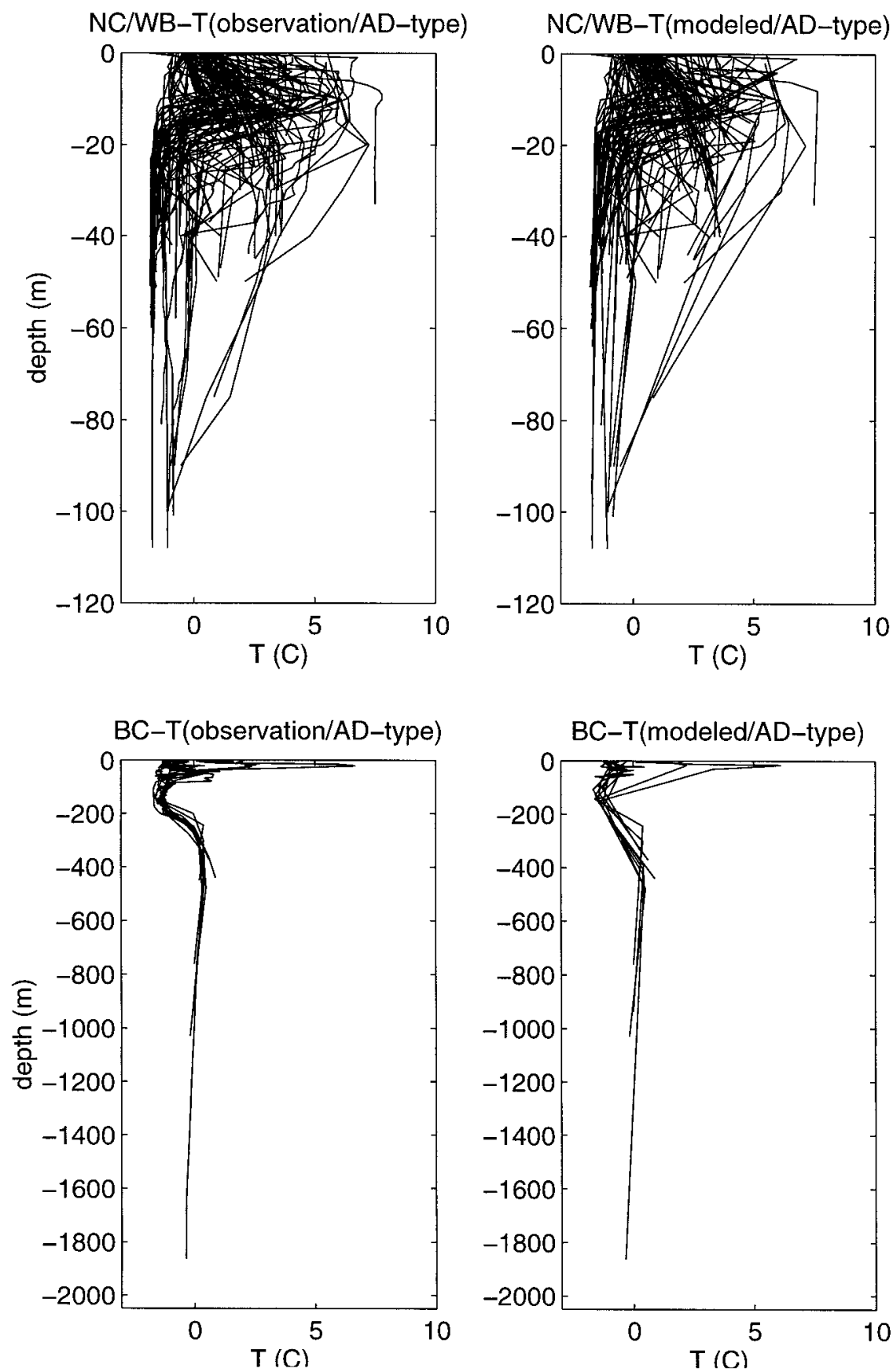

FIG. 9. August AD-type observed $T$ profiles and corresponding modeled profiles: (a) NC/WB shelf region observed profiles, (b) NC/WB shelf region modeled profiles, (c) deep water observed profiles, and (e) deep water modeled profiles. The rmse's are listed in Table 5.

$\left.\left(d_{2}^{S}-d_{1}^{S}\right), G_{\text {ha }}\right]$ for the southern Chukchi Sea shelf. The horizontal axis in each figure represents the corresponding parameters. The vertical axis is the frequency. There are 187 temperature profiles passing both $t$ - and $F$-tests. The thermal mixed layer depth $\left(\mathrm{MLD}^{T}\right)$ varies from 0 (no thermal mixed layer) to $40 \mathrm{~m}$ with a mean value of $10.1 \mathrm{~m}$ (Fig. 13a), the temperature jump at the mixed layer base $(\Delta T)$ varies from $0^{\circ}$ (no thermal mixed layer) to $4.5^{\circ} \mathrm{C}$ with a mean value of $0.72^{\circ} \mathrm{C}$ (Fig. $13 \mathrm{~b}$ ), the thermocline thickness $\left(d_{2}^{T}-d_{1}^{T}\right)$ varies from 2 to $44 \mathrm{~m}$ with a mean value of $11.9 \mathrm{~m}$ (Fig. 13c), and the thermocline gradient $\left(G_{\mathrm{th}}\right)$ varies from near 0 to $1.75^{\circ} \mathrm{C} \mathrm{m}^{-1}$ (Fig. 13d) with a mean value of $0.43^{\circ} \mathrm{C} \mathrm{m}^{-1}$.

In August, there are 205 DM-type and 61 SM-type salinity profiles (Table 2). For the SM-type profiles, $\mathrm{MLD}^{s}$ changes from 0 (no salinity mixed layer) to 14 

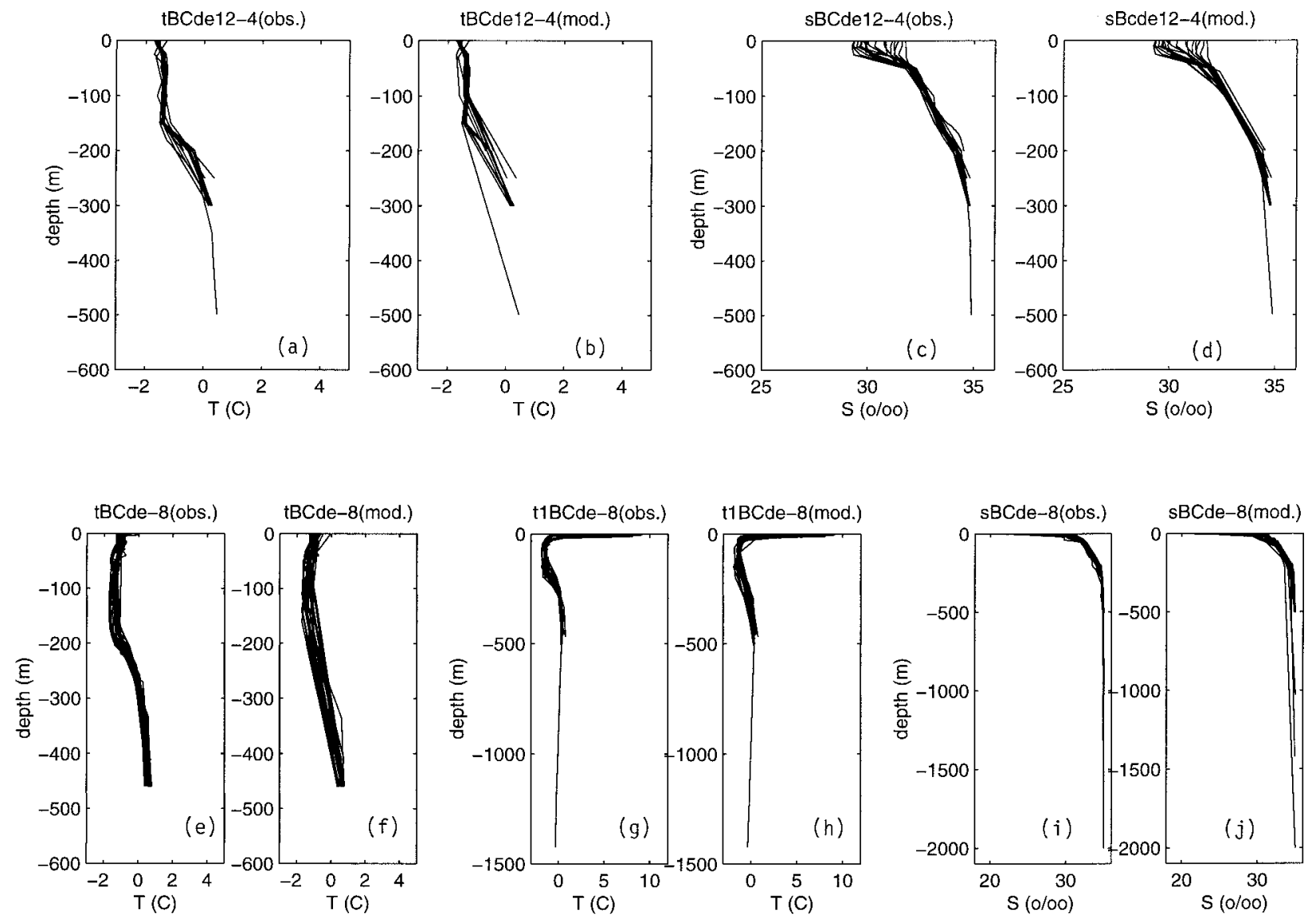

FIG. 10. Winter (Nov-Apr) and summer (Aug) deep water observed and modeled $T, S$ profiles: (a) observed winter $T$ profiles, (b) modeled winter $T$ profiles, (c) observed winter $S$ profiles, (d) modeled winter $S$ profiles, (e) observed summer DM-type $T$ profiles, (f) modeled summer DM-type $T$ profiles, (g) observed summer SM-type $T$ profiles, (h) modeled summer SM-type $T$ profiles, (i) observed summer $S$ profiles, and (j) modeled summer $S$ profiles. The rmse's are listed in Tables 5 and 6.

$\mathrm{m}$ with a mean value of $5.0 \mathrm{~m}$ (Fig. 13e), the salinity jump at the mixed layer base $(\Delta S)$ varies from 0 (no salinity mixed layer) to $1.8 \mathrm{psu}$ with a mean value of 0.20 psu (Fig. 13f), the halocline thickness $\left(d_{2}^{S}-d_{1}^{S}\right)$ varies from 3 to $45 \mathrm{~m}$ with a mean value of $10.2 \mathrm{~m}$ (Fig. 13g), and the halocline gradient $\left(G_{\text {ha }}\right)$ varies from near 0 to $1.48 \mathrm{psu} \mathrm{m}^{-1}$ with a mean value of $0.40 \mathrm{psu}$ $\mathrm{m}^{-1}$ (Fig. 13h).

\section{2) Northern Chukchi/western Beaufort Sea SHELF}

Figure 14 exhibits the thermohaline features for the northern Chukchi/western Beaufort Sea shelf. There are 162 temperature profiles passing the $t$ - and $F$-tests. $\mathrm{MLD}^{T}$ varies from 0 (no thermal mixed layer) to $28 \mathrm{~m}$ with a mean value of $7.7 \mathrm{~m}$ (Fig. 14a), $\Delta T$ varies from $0^{\circ}$ (no thermal mixed layer) to $6.5^{\circ} \mathrm{C}$ with a mean value of $0.62^{\circ} \mathrm{C}$ (Fig. 14b), the thermocline thickness $\left(d_{2}^{T}-\right.$ $\left.d_{1}^{T}\right)$ varies from 3 to $47 \mathrm{~m}$ with a mean value of $14.0 \mathrm{~m}$ (Fig. 14c), and $G_{\mathrm{th}}$ varies from near 0 to $1.7^{\circ} \mathrm{C} \mathrm{m}^{-1}$ (Fig. 14d) with a mean value of $0.33^{\circ} \mathrm{C} \mathrm{m}^{-1}$. There are 252 salinity profiles passing the $t$ - and $F$-tests. MLD ${ }^{s}$ changes from 0 (no salinity mixed layer) to $20 \mathrm{~m}$ with a mean value of $4.7 \mathrm{~m}$ (Fig. 14e), $\Delta S$ varies from 0 (no salinity mixed layer) to 7.8 psu with a mean value of $0.55 \mathrm{psu}$ (Fig. 14f), the halocline thickness $\left(d_{2}^{S}-d_{1}^{S}\right)$ varies from 2 to $110 \mathrm{~m}$ with a mean value of $18.4 \mathrm{~m}$ (Fig. 14g), and $G_{\text {ha }}$ varies from near 0 to $1.32 \mathrm{psu} \mathrm{m}^{-1}$ with a mean value of $0.36 \mathrm{psu} \mathrm{m}^{-1}$ (Fig. 14h).

\section{3) Eastern Beaufort Sea Shelf}

Figure 15 exhibits the subsurface parameters for the eastern Beaufort Sea shelf. There are 128 temperature profiles passing the $t$ - and $F$-tests. For the thermal structure, $\mathrm{MLD}^{T}$ varies from 0 (no thermal mixed layer) to $15 \mathrm{~m}$ with a mean value of $5.6 \mathrm{~m}$ (Fig. 15a), $\Delta T$ varies from $0^{\circ}$ (no thermal mixed layer) to $4.4^{\circ} \mathrm{C}$ with a mean value of $0.43^{\circ} \mathrm{C}$ (Fig. 15b), the thermocline thickness $\left(d_{2}^{T}-d_{1}^{T}\right)$ varies from 2 to $100 \mathrm{~m}$ with a mean value of $11.3 \mathrm{~m}$ (Fig. $15 \mathrm{c}$ ), and $G_{\mathrm{th}}$ varies from near 0 to $1.83^{\circ} \mathrm{C}$ $\mathrm{m}^{-1}$ (Fig. 15d) with a mean value of $0.65^{\circ} \mathrm{C} \mathrm{m}^{-1}$. There are 100 salinity profiles passing the $t$ - and $F$-tests. For 

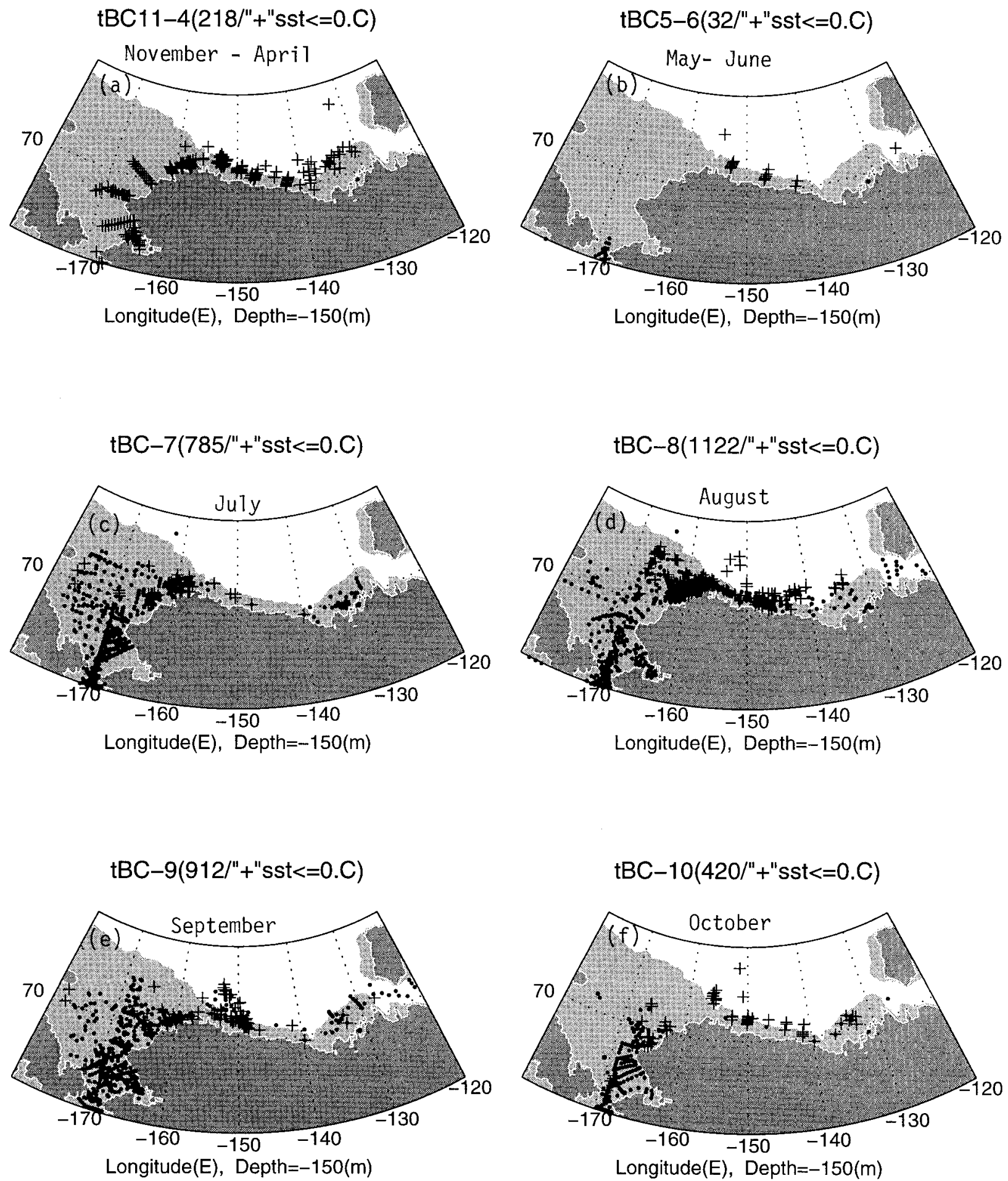

FIG. 11. Seasonal variation of SST presented by warm water (SST $>0^{\circ} \mathrm{C}$, denoted by "') and cold water (SST $\leq 0^{\circ} \mathrm{C}$, denoted by "+"). Data were obtained from the MOODS for 1970-93. 

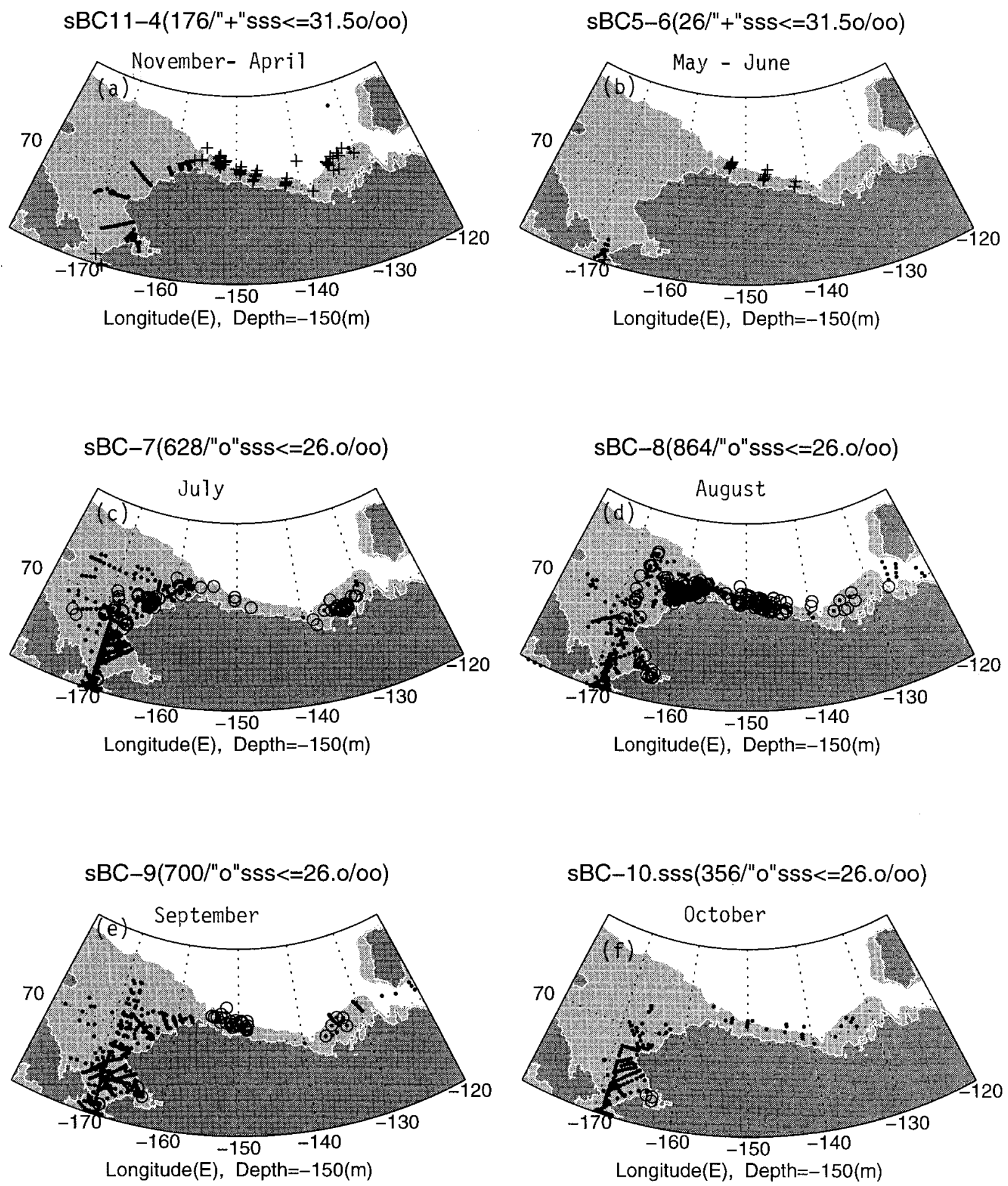

FIG. 12. Seasonal variation of SSS, presented by salty water (denoted by is 31.5 psu for Nov-Jun and 26 psu for Jul-Oct. Data were obtained from the MOODS for the years 1970-93.

the salinity structure, $\mathrm{MLD}^{s}$ changes from 0 (no salinity mixed layer) to $12 \mathrm{~m}$ with a mean value of $4.5 \mathrm{~m}$ (Fig. $15 \mathrm{e}$ ), $\Delta S$ varies from 0 (no salinity mixed layer) to 4.0 psu with a mean value of 0.40 psu (Fig. 15f), the halo- cline thickness $\left(d_{2}^{S}-d_{1}^{S}\right)$ changes from 3 to $78 \mathrm{~m}$ with a mean value of $9.6 \mathrm{~m}$ (Fig. $15 \mathrm{~g}$ ), and $G_{\text {ha }}$ changes from near 0 to $3.30 \mathrm{psu} \mathrm{m}^{-1}$ with a mean value of $0.70 \mathrm{psu}$ $\mathrm{m}^{-1}$ (Fig. 15h). 

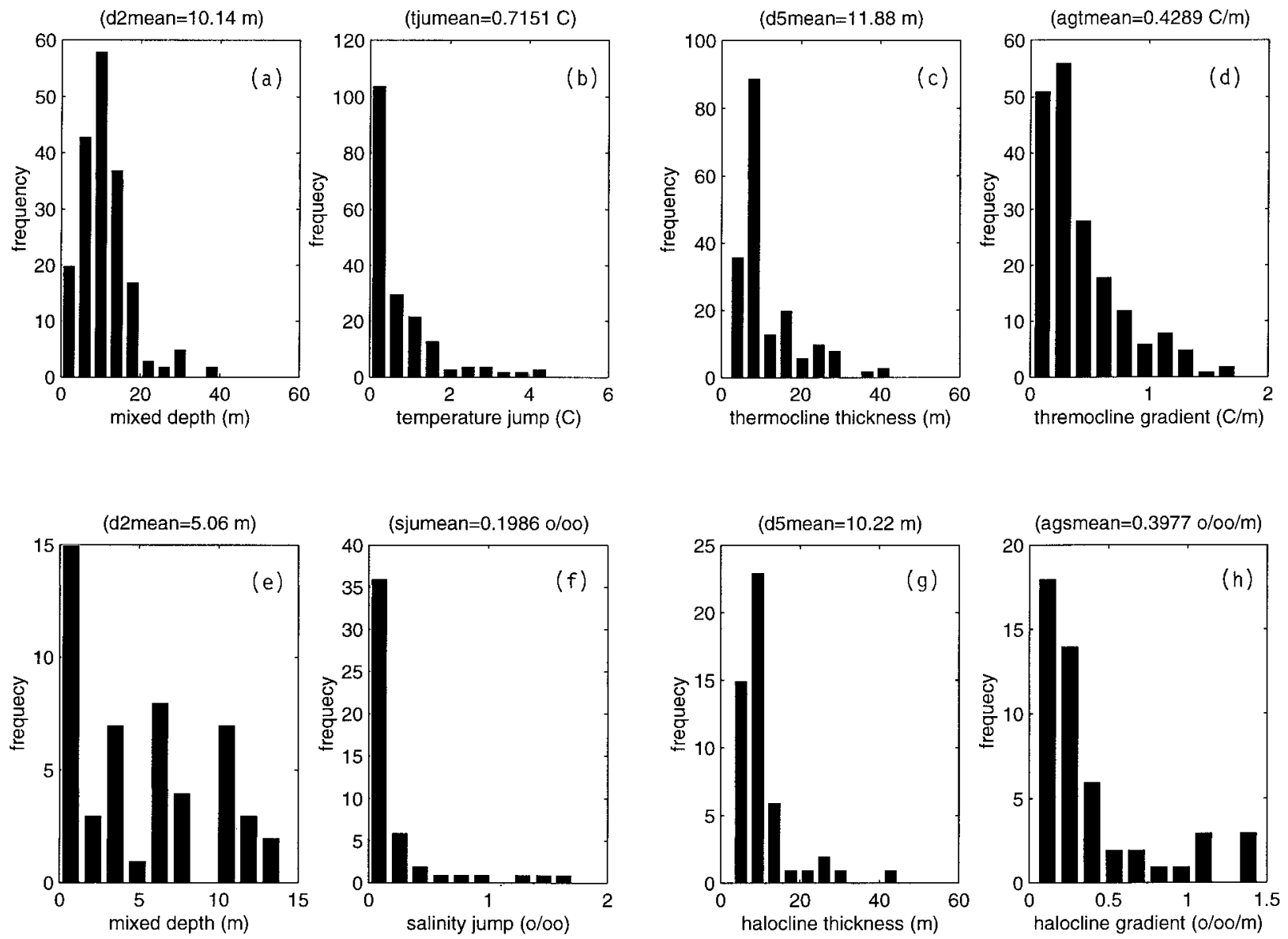

FIG. 13. Histograms of various parameters of Aug southern Chukchi Sea shelf thermohaline feature obtains by the geometric model: (a) temperature mixed layer depth $(\mathrm{m}), \mathrm{MLD}^{T}$; (b) temperature jump at mixed layer base $\left({ }^{\circ} \mathrm{C}\right), \Delta T$; (c) thermocline thickness $(\mathrm{m})$; (d) thermocline gradient $\left({ }^{\circ} \mathrm{C} \mathrm{m}^{-1}\right)$; (e) salinity mixed layer depth $(\mathrm{m}), \mathrm{MLD}^{s}$; (f) salinity jump at mixed layer base (psu), $\Delta S$; (g) upper-halocline thickness $(\mathrm{m})$; and (h) halocline gradient $\left[\mathrm{psu} \mathrm{m}^{-1}\right]$.

\section{c. Summer (August) deep water thermohaline structure}

Figure 16 exhibits the subsurface parameters for the Beaufort Sea deep water. There are only 24 SM-type temperature profiles passing the $t$ - and $F$-tests. For the thermal structure, $\mathrm{MLD}^{T}$ varies from 0 (no thermal mixed layer) to $5 \mathrm{~m}$ with a mean value of $1.3 \mathrm{~m}$ (Fig. 16a), $\Delta T$ varies from $0^{\circ}$ (no thermal mixed layer) to $4.0^{\circ} \mathrm{C}$ with a mean value of $0.26^{\circ} \mathrm{C}$ (Fig. 16b), the upper thermocline thickness $\left(d_{2}^{T}-d_{1}^{T}\right)$ varies from 2 to 240 $\mathrm{m}$ with a mean value of $67.3 \mathrm{~m}$ (Fig. 16c), and $G_{\mathrm{th}}^{U}$ varies from near 0 to $0.4^{\circ} \mathrm{C} \mathrm{m}^{-1}$ (Fig. 14d) with a mean value of $0.19^{\circ} \mathrm{C} \mathrm{m}^{-1}$.

There are 19 salinity profiles passing the $t$ - and $F$ test. For the salinity structure, $\mathrm{MLD}^{s}$ changes from 0 (no salinity mixed layer) to $5 \mathrm{~m}$ with a mean value of $0.84 \mathrm{~m}$ (Fig. 16e), $\Delta S$ varies from 0 (no salinity mixed layer) to $0.1 \mathrm{psu}$ with a mean value of 0.0053 psu (Fig. 16f), the upper halocline thickness $\left(d_{2}^{S}-d_{1}^{S}\right)$ varies from 9 to $25 \mathrm{~m}$ with a mean value of $13.5 \mathrm{~m}$ (Fig. $16 \mathrm{~g}$ ), and
$G_{\text {ha }}^{U}$ varies from near 0 to $0.58 \mathrm{psu} \mathrm{m}^{-1}$ with a mean value of $0.31 \mathrm{psu} \mathrm{m}^{-1}$ (Fig. 16h).

These thermohaline features of both shelf water and deep water are outlined in Tables 7 and 8 .

\section{Conclusions}

Based on geometric characteristics of profiles (minimum and maximum $\left.\partial^{2} T / \partial z^{2}, \partial^{2} S / \partial z^{2}\right)$, several key depths such as MLD, top and bottom of upper thermocline, and halocline can be identified. Below the upper thermocline, we use $T_{\min }, T_{\max }$ to determine the top and bottom of the lower thermocline. Other thermohaline features such as temperature and salinity jumps at the mixed layer base $(\Delta T, \Delta S)$, upper- and lowerthermocline/halocline gradients can also be identified.

The thermohaline geometric model depicted in this paper demonstrates a good capability to compress a large dataset into a small enough volume of physically meaningful data such that the investigators may readily 

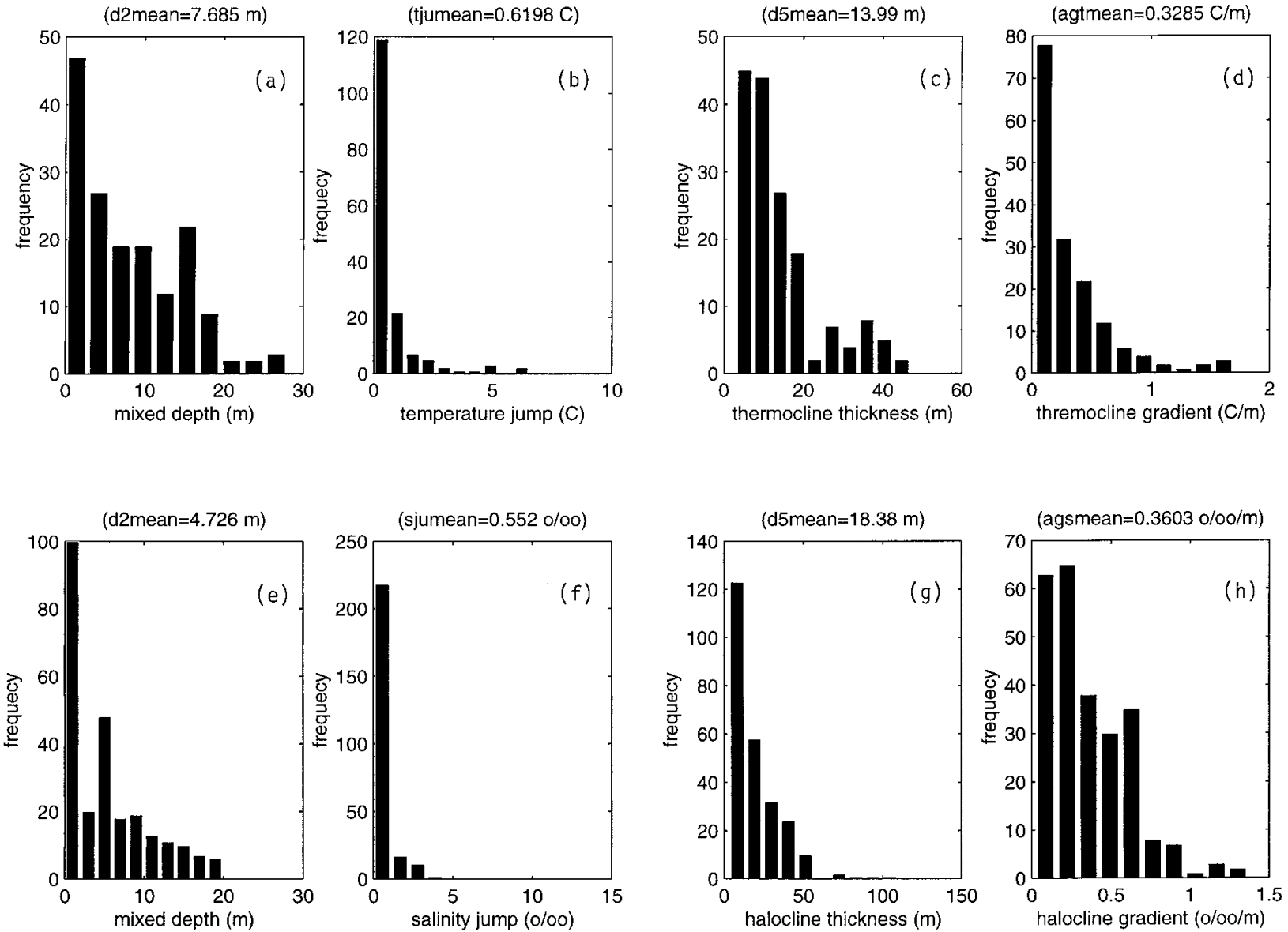

FIG. 14. Histograms of various parameters of Aug northern Chukchi/western Beaufort Sea shelf thermohaline feature obtains by the geometric model: (a) temperature mixed layer depth $(\mathrm{m}), \mathrm{MLD}^{T}$; (b) temperature jump at mixed layer base $\left({ }^{\circ} \mathrm{C}\right), \Delta T$; (c) thermocline thickness (m); (d) thermocline gradient $\left({ }^{\circ} \mathrm{C} \mathrm{m}^{-1}\right)$; (e) salinity mixed layer depth (m), MLD ${ }^{s}$; (f) salinity jump at mixed layer base (psu), $\Delta S$; (g) halocline thickness $(\mathrm{m})$; and $(\mathrm{h})$ halocline gradient $\left[\mathrm{psu} \mathrm{m}^{-1}\right]$.

assimilate and interpret it. Furthermore, the geometric model can process multiple type profiles. The overall root-mean-square errors of the geometric temperature model is $0.18^{\circ} \mathrm{C}$ for the shelf water, and $0.12^{\circ} \mathrm{C}$ (winter) to $0.3^{\circ} \mathrm{C}$ (summer) for the deep water. The overall rootmean-square error of the geometric salinity model is 0.16 psu for the shelf water, 0.14 psu (winter) to 0.22 psu (summer) for the deep water.

The Beaufort/Chukchi Sea shelf water experiences a strong seasonal variation. The geometric model proposed here clearly shows large thermohaline variabilities and the multiple structures. During the winter season (November-April), the surface mixed layer for both $T$ and $S$ extends from the surface to bottom. During the other seasons (May-October), the ocean mixed layer shoals. Two distinguishing processes (surface warming and horizontal advection) make two types of multilayer temperature profiles (shallow-mixing type caused by the surface warming, and advection type caused by a strong sublayer advection) and only one type of multilayer sa- linity profiles (shallow mixing). During summer (August), the mean thermal mixed layer depth shoals from $10.1 \mathrm{~m}$ for the southern Chukchi Sea shelf to $7.7 \mathrm{~m}$ for the northern Chukchi/western Beaufort Sea shelf, and further reduces to $5.6 \mathrm{~m}$ for the eastern Beaufort Sea shelf. The salinity mixed layer depth is usually thinner than the thermal mixed layer depth in the northern Chukchi/western Beaufort and the eastern Beaufort Sea shelf (mean value $4.6 \mathrm{~m}$ ), but thicker than the thermal mixed layer in the southern Chukchi Sea, where $77 \%$ of $S$ profiles have a one-layer structure (mixed layer depth is the same as the water depth).

The upper portion $(z>-150 \mathrm{~m})$ of the Beaufort/ Chukchi Sea deep water experiences a seasonal variation; however, the lower portion $(z \leq-150 \mathrm{~m})$ does not have an evident seasonal variation. During the winter season (November-April), the surface thermal mixed layer $(\sim 170 \mathrm{~m})$ is much deeper than the surface salinity mixed layer $(\sim 30 \mathrm{~m})$. During the other seasons (MayOctober), the ocean mixed layer shoals. There are two 

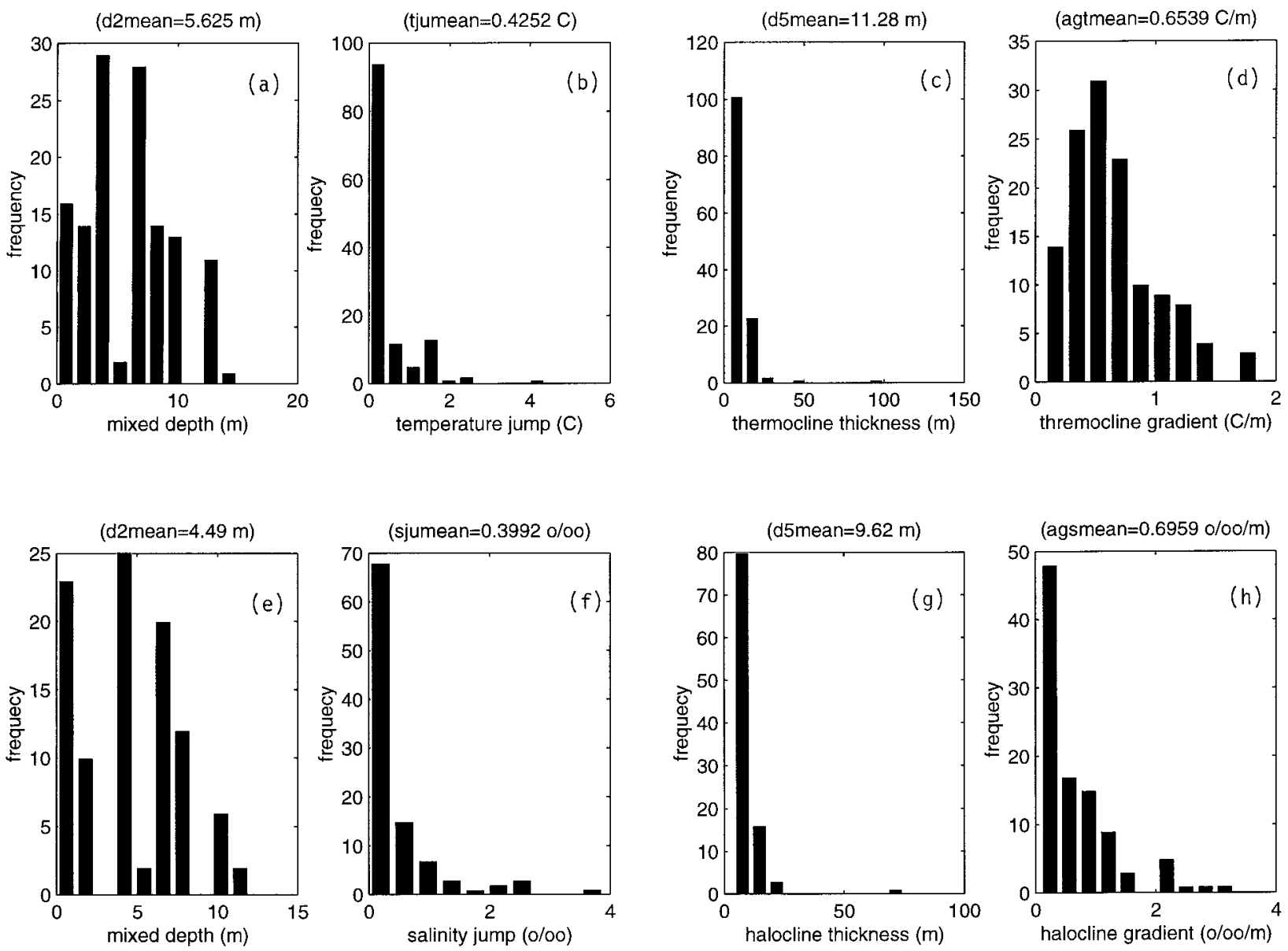

FIG. 15. Histograms of various parameters of Aug eastern Beaufort Sea shelf thermohaline feature obtains by the geometric model: (a) temperature mixed layer depth (m), $\mathrm{MLD}^{T}$; (b) temperature jump at mixed layer base $\left({ }^{\circ} \mathrm{C}\right), \Delta T$; (c) thermocline thickness (m); (d) thermocline gradient $\left({ }^{\circ} \mathrm{C} \mathrm{m}^{-1}\right)$; (e) salinity mixed layer depth (m), $\mathrm{MLD}^{s}$; (f) salinity jump at mixed layer base (psu), $\Delta S$; (g) halocline thickness (m); and (h) halocline gradient [psu $\left.\mathrm{m}^{-1}\right]$.

types of multilayer temperature profiles (shallow-mixing and advection types) and only one type of multilayer salinity profiles (shallow mixing). During summer (August), the upper thermocline and halocline almost reach the surface for the shallow mixing type $T, S$ profiles. The mean thermal and salinity mixed layer depths are 1.3 and $0.8 \mathrm{~m}$, respectively.

Strong temperature and salinity jumps at the mixed layer base appear in the summer season. The mean values of $\Delta T, \Delta S$ of August profiles are around $0.72^{\circ} \mathrm{C}$, $0.20 \mathrm{psu}$ in the southern Chukchi Sea shelf; $0.62^{\circ} \mathrm{C}, 0.55$

TABLE 7. Mean values of thermal parameters for three shelf regions and deep water in Aug.

\begin{tabular}{lcccc}
\hline \hline & $\mathrm{MLD}^{T}(\mathrm{~m})$ & $\Delta T\left({ }^{\circ} \mathrm{C}\right)$ & $d_{2}^{T}-d_{1}^{T}$ & $G_{\mathrm{th}}^{U}$ \\
\hline SC shelf & 10.1 & 0.72 & 11.9 & 0.43 \\
NC/WB shelf & 7.7 & 0.62 & 14.0 & 0.33 \\
EB shelf & 5.6 & 0.43 & 11.3 & 0.65 \\
Deep water & 1.3 & 0.26 & 67.3 & 0.19 \\
\hline
\end{tabular}

psu in the northern Chukchi-western Beaufort Sea shelf; and $0.43^{\circ} \mathrm{C}, 0.40 \mathrm{psu}$ in the eastern Beaufort Sea shelf.

Strong upper thermocline/halocline gradients are found in the summer season. Both upper-thermocline and halocline gradients $\left(G_{\mathrm{th}}^{U}, G_{\mathrm{ha}}^{U}\right)$ weaken from the southern Chukchi Sea shelf $\left[0.43^{\circ} \mathrm{C} \mathrm{m}^{-1}, 0.40 \mathrm{psu} \mathrm{m}^{-1}\right]$ to the northern Chukchi/western Beaufort Sea shelf $\left[0.33^{\circ} \mathrm{C} \mathrm{m}^{-1}, 0.36 \mathrm{psu} \mathrm{m}^{-1}\right]$, and then strengthen from the northern Chukchi/western Beaufort Sea shelf to the eastern Beaufort Sea shelf $\left[0.65^{\circ} \mathrm{C} / \mathrm{m}^{-1}, 0.70 \mathrm{psu} \mathrm{m}^{-1}\right]$.

TABLE 8. Mean values of haline parameters for three shelf regions and deep water in Aug.

\begin{tabular}{|c|c|c|c|c|}
\hline & $\operatorname{MLD}^{s}(\mathrm{~m})$ & $\Delta S(\mathrm{psu})$ & $d_{2}^{S}-d_{1}^{S}$ & $\begin{array}{c}G_{\mathrm{ha}}^{U} \\
\left(\mathrm{psu} \mathrm{m}^{-1}\right)\end{array}$ \\
\hline SC shelf & 5.1 & 0.20 & 10.2 & 0.40 \\
\hline NC/WB shelf & 4.7 & 0.55 & 18.4 & 0.36 \\
\hline EB shelf & 4.5 & 0.40 & 9.6 & 0.70 \\
\hline Deep water & 0.8 & 0.01 & 13.5 & 0.31 \\
\hline
\end{tabular}



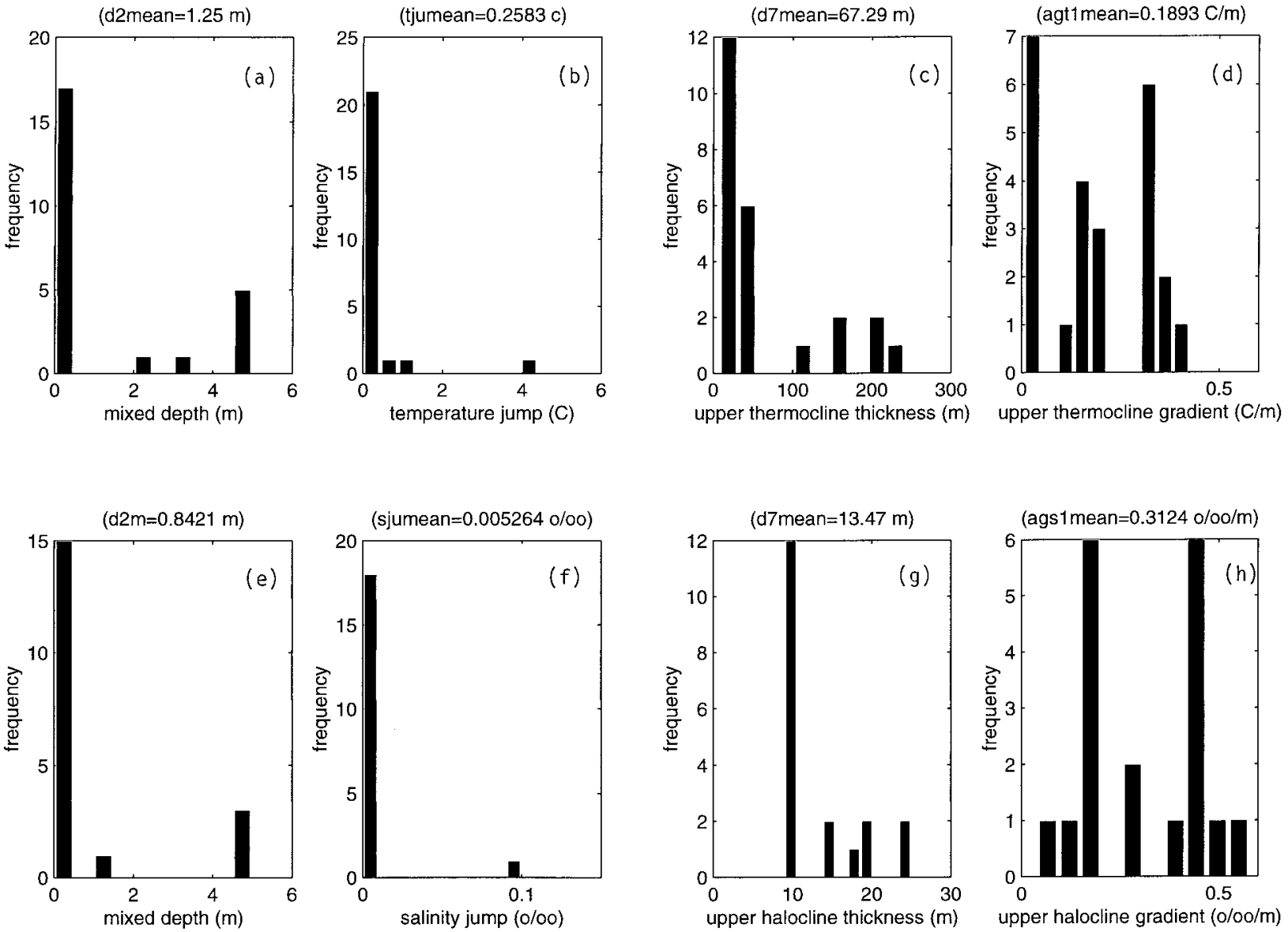

FIG. 16. Histograms of various parameters of Aug Beaufort/Chukchi Sea deep water SM-type profiles obtains by the geometric model: (a) temperature mixed layer depth (m), $\operatorname{MLD}^{T}$; (b) temperature jump at mixed layer base $\left({ }^{\circ} \mathrm{C}\right), \Delta T$; (c) upper-thermocline thickness (m); (d) upper-thermocline gradient $\left({ }^{\circ} \mathrm{C} \mathrm{m}^{-1}\right)$; (e) salinity mixed layer depth (m), $\mathrm{MLD}^{s}$; (f) salinity jump at mixed layer base (psu), $\Delta S$; (g) upperhalocline thickness $(\mathrm{m})$; and $(\mathrm{h})$ upper-halocline gradient $\left[\mathrm{psu} \mathrm{m}^{-1}\right]$.

It is a challenge to interpolate/extrapolate profile data horizontally and the profile parameterization may help. Thus, the geometric (or parametric) model is useful in building temperature and salinity climatology such as GDEM.

This geometric model can also be used to process output from any dynamical model and to obtain meaningful products, that is, mixed layer depth, upper- and lower-thermocline/halocline depths and strengths, and deep layer stratification.

Acknowledgments. The authors are grateful to Yongfu Qian and C. W. Fan at the Naval Postgraduate School for programming assistance. This work was funded by the Office of Naval Research (ONR) High Latitude (HL) Program through the Surface Heat Budget of the Arctic Ocean (SHEBA) Experiment and by the ONR Naval Ocean Modeling and Prediction (NOMP) Program.

\section{REFERENCES}

Aagaard, K., 1984: The Beaufort undercurrent. The Alaskan Beaufort Sea, P. W. Barnes, D. M. Schell, and E. Reimnitz, Eds., Academic Press, 47-72.

Chu, P. C., 1995: A feature model for Arctic upper-ocean thermal structure. Proc. Fourth Conf. on Polar Meteorology and Oceanography, Dallas, TX, Amer. Meteor. Soc., 224-227.

- and R. W. Garwood Jr., 1991: On the two-phase thermodynamics of the coupled cloud-ocean mixed layer. J. Geophys. Res., 96, 3425-3436.

— C. C. R. Fralick Jr., S. D. Haeger, and M. J. Carron, 1997: A parametric model for the Yellow Sea thermal variability. J. Geophys. Res., 102, $10499-10507$.

Coachman, L. K., and C. A. Barnes, 1961: The contribution of Bering Sea water to the Arctic Ocean. Arctic, 14, 147-161.

Maykut, G. A., and M. G. McPhee, 1995: Solar heating of the Arctic mixed layer. J. Geophys. Res., 100, 24 691-24 703.

Mountain, D. G., L. K. Coachman, and K. Aagaard, 1976: On the flow through Barrow Canyon. J. Phys. Oceanogr., 6, 461-470.

Paquette, R. G., and R. H. Bourke, 1974: Observations on the coastal current of Arctic Alaska. J. Mar. Res., 32, 195-207.

Teague, W. J., M. J. Carron, and P. J. Hogan, 1990: A comparison between the Generalized Digital Environmental Model and Levitus climatologies. J. Geophys. Res., 95, 7167-7183. 